\title{
Differential-output $B$-dot and $D$-dot monitors for current and voltage measurements on a 20-MA, 3-MV pulsed-power accelerator
}

\author{
T. C. Wagoner, ${ }^{1}$ W. A. Stygar, ${ }^{2}$ H. C. Ives, ${ }^{3}$ T. L. Gilliland, ${ }^{1}$ R. B. Spielman, ${ }^{1}$ M. F. Johnson, ${ }^{4}$ P. G. Reynolds, ${ }^{4}$ J. K. Moore, ${ }^{1}$ \\ R. L. Mourning, ${ }^{1}$ D. L. Fehl, ${ }^{2}$ K. E. Androlewicz, ${ }^{1}$ J.E. Bailey, ${ }^{2}$ R. S. Broyles, ${ }^{1}$ T. A. Dinwoodie, ${ }^{1}$ G. L. Donovan, ${ }^{2}$ \\ M. E. Dudley, ${ }^{1}$ K. D. Hahn, ${ }^{2}$ A. A. Kim,${ }^{5}$ J. R. Lee, ${ }^{2}$ R. J. Leeper, ${ }^{2}$ G. T. Leifeste, ${ }^{2}$ J. A. Melville, ${ }^{6}$ J. A. Mills, ${ }^{2}$ L. P. Mix, ${ }^{2}$ \\ W. B. S. Moore, ${ }^{2}$ B. P. Peyton, ${ }^{1}$ J. L. Porter, ${ }^{2}$ G. A. Rochau, ${ }^{2}$ G. E. Rochau, ${ }^{2}$ M. E. Savage, ${ }^{2}$ J. F. Seamen, ${ }^{2}$ J. D. Serrano, ${ }^{1}$ \\ A. W. Sharpe, ${ }^{2}$ R. W. Shoup, ${ }^{7}$ J. S. Slopek, ${ }^{1}$ C. S. Speas, ${ }^{2}$ K. W. Struve, ${ }^{2}$ D. M. Van De Valde, ${ }^{3}$ and R. M. Woodring ${ }^{1}$ \\ ${ }^{1}$ Ktech Corporation, Albuquerque, New Mexico 87123, USA \\ ${ }^{2}$ Sandia National Laboratories, Albuquerque, New Mexico 87185, USA \\ ${ }^{3} E G \& G$, Albuquerque, New Mexico 87107, USA \\ ${ }^{4}$ Team Specialty Products Corporation, Albuquerque, New Mexico 87123, USA \\ ${ }^{5}$ Institute of High Current Electronics, Russian Academy of Sciences, Tomsk 634055, Russia \\ ${ }^{6}$ Prodyn Technologies Incorporated, Albuquerque, New Mexico 87107, USA \\ ${ }^{7}$ ITT Industries, Albuquerque, New Mexico 87110, USA \\ (Received 20 January 2008; published 22 October 2008)
}

\begin{abstract}
We have developed a system of differential-output monitors that diagnose current and voltage in the vacuum section of a 20-MA 3-MV pulsed-power accelerator. The system includes 62 gauges: 3 current and 6 voltage monitors that are fielded on each of the accelerator's 4 vacuum-insulator stacks, 6 current monitors on each of the accelerator's 4 outer magnetically insulated transmission lines (MITLs), and 2 current monitors on the accelerator's inner MITL. The inner-MITL monitors are located $6 \mathrm{~cm}$ from the axis of the load. Each of the stack and outer-MITL current monitors comprises two separate $B$-dot sensors, each of which consists of four 3-mm-diameter wire loops wound in series. The two sensors are separately located within adjacent cavities machined out of a single piece of copper. The high electrical conductivity of copper minimizes penetration of magnetic flux into the cavity walls, which minimizes changes in the sensitivity of the sensors on the 100-ns time scale of the accelerator's power pulse. A model of flux penetration has been developed and is used to correct (to first order) the $B$-dot signals for the penetration that does occur. The two sensors are designed to produce signals with opposite polarities; hence, each current monitor may be regarded as a single detector with differential outputs. Common-mode-noise rejection is achieved by combining these signals in a 50- $\Omega$ balun. The signal cables that connect the $B$-dot monitors to the balun are chosen to provide reasonable bandwidth and acceptable levels of Compton drive in the bremsstrahlung field of the accelerator. A single 50- $\Omega$ cable transmits the output signal of each balun to a double-wall screen room, where the signals are attenuated, digitized (0.5-ns/sample), numerically compensated for cable losses, and numerically integrated. By contrast, each inner-MITL current monitor contains only a single $B$-dot sensor. These monitors are fielded in opposite-polarity pairs. The two signals from a pair are not combined in a balun; they are instead numerically processed for common-mode-noise rejection after digitization. All the current monitors are calibrated on a 76-cmdiameter axisymmetric radial transmission line that is driven by a 10-kA current pulse. The reference current is measured by a current-viewing resistor (CVR). The stack voltage monitors are also differentialoutput gauges, consisting of one 1.8 -cm-diameter $D$-dot sensor and one null sensor. Hence, each voltage monitor is also a differential detector with two output signals, processed as described above. The voltage monitors are calibrated in situ at $1.5 \mathrm{MV}$ on dedicated accelerator shots with a short-circuit load. Faraday's law of induction is used to generate the reference voltage: currents are obtained from calibrated outerMITL $B$-dot monitors, and inductances from the system geometry. In this way, both current and voltage measurements are traceable to a single CVR. Dependable and consistent measurements are thus obtained with this system of calibrated diagnostics. On accelerator shots that deliver 22 MA to a low-impedance $z$-pinch load, the peak lineal current densities at the stack, outer-MITL, and inner-MITL monitor locations are $0.5,1$, and $58 \mathrm{MA} / \mathrm{m}$, respectively. On such shots the peak currents measured at these three locations agree to within $1 \%$.
\end{abstract}

DOI: 10.1103/PhysRevSTAB.11.100401

PACS numbers: 84.37.+q, 84.70.+p, 07.55.-w, 07.50.-e

\section{INTRODUCTION}

Multiterawatt pulsed-power accelerators (such as the 55-TW $Z$ machine [1-9]) are used to drive inertialconfinement-fusion, material-science, radiation-physics, radiation-effects, advanced-radiography, astrophysics, and other high-energy-density-physics experiments. The $Z$ accelerator delivers as much as $2 \mathrm{MJ}$ of electromagnetic energy in a 100-ns pulse to a physics package (i.e., the load) for such experiments. 
Pulsed-power accelerators typically incorporate a vacuum-power-flow section that includes one or more self-magnetically insulated transmission lines (MITLs) $[1,2,4,9]$ and a vacuum-insulator stack [1,2,4-9]. The stack serves as the hermetic interface that separates the region under vacuum from the rest of the accelerator. For such machines, the vacuum section is that which operates at the highest electromagnetic-power densities; it is also that which couples the electromagnetic power and energy generated by the accelerator to the load.

It is often useful to measure current and voltage as a function of time in the vacuum section as part of the effort to monitor accelerator performance [10-13]. Since the vacuum section is that which connects directly to the physics package, current and voltage measurements in this region of the accelerator also provide a more complete understanding of the experiments that are conducted on the machine [11-13].

In this article we describe in detail a diagnostic package $[10,11]$ that was designed to measure current and voltage in the vacuum section of the $Z$ pulsed-power accelerator. An idealized representation of the $Z$ vacuum section is given by Fig. 1. As indicated by the figure, the vacuum section comprises 4 3.35-m-diameter vacuum-insulator stacks, 4 outer MITLs, a double-post-hole vacuum convolute, an inner MITL, and the load [1,2,4-9]. The vacuum section has been used to drive various types of loads; Fig. 1 arbitrarily assumes the load is a $z$ pinch. (We define the outer MITLs to be those located upstream of the convolute $[1,2,4,9]$. The convolute is a structure [14-20] that connects the four outer MITLs in parallel, combines the MITL output currents, and delivers the combined current to the

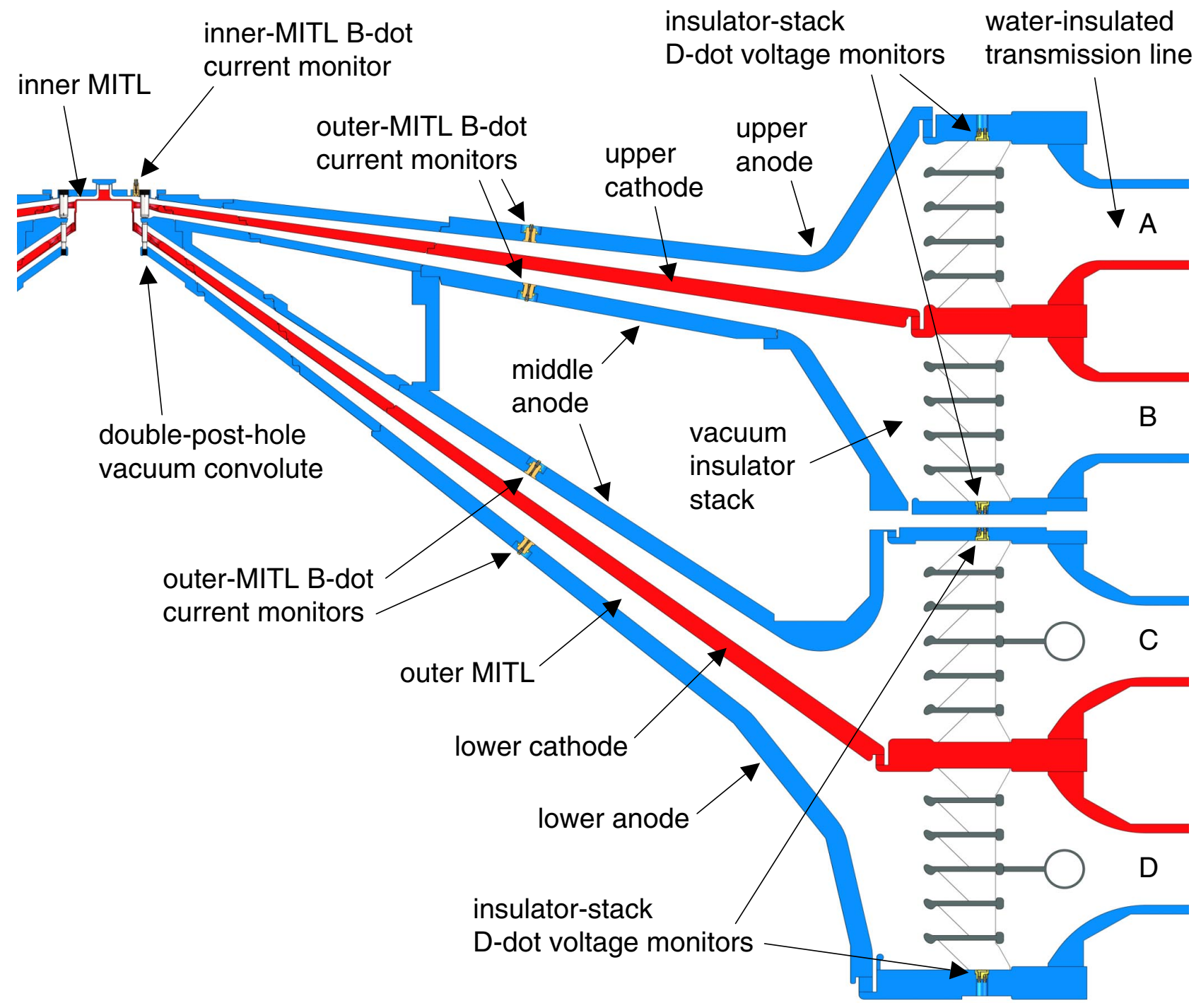

FIG. 1. (Color) Cross-sectional view of the four-level vacuum-power-flow section of the $Z$ pulsed-power accelerator [1,2,4-9]. Each level includes a vacuum-insulator stack and an outer MITL. This view shows the locations of the insulator-stack $D$-dot, outer-MITL $B$-dot, and inner-MITL $B$-dot monitors. The stack $B$-dots (which are not pictured here) are located at the same radial location as that of the stack $D$-dots, but at different azimuthal locations. The outer diameter of the insulator stack is $3.35 \mathrm{~m}$. 
inner MITL. We define the inner MITL to be that which is located downstream of the convolute $[1,2,4,9,11]$. The inner MITL, which is a few centimeters long, delivers the combined current from the convolute to the load.)

On a typical $Z$-accelerator shot, the nominal total current in the four-level stack-MITL system is 20 MA. The nominal voltage across each of the 4 insulator stacks is $3 \mathrm{MV}$. The diagnostic package has been successfully tested at these current and voltage levels on over 1700 accelerator shots. Although the package was designed specifically for use on $Z$, the monitor designs can be readily adapted for use on other accelerators.

The diagnostic package consists of differential-output $B$-dot and $D$-dot monitors that measure the current and voltage, respectively, at each of the 4 insulator stacks; differential-output $B$-dot monitors that measure the current at each of the 4 outer MITLs; and 2 opposite-polarity $B$-dot monitors that measure the current at the inner MITL. The differential-output monitor designs were motivated by the previously reported differential-output $B$-dot monitor of Rochau, Mowrer, and Webb [21]. Other successful current and voltage diagnostics developed for pulsed-power applications are described in Refs. [22-78].

The present article is organized as follows. The locations of the monitors are discussed in Sec. II. The stack and outer-MITL $B$-dot monitor designs are essentially identical except for the outer dimensions of the monitor bodies. Section III describes the outer-MITL monitor, presents a lumped-circuit model for analyzing its signals, and explains its calibration. Sections IV and V similarly describe the inner-MITL $B$-dot monitor and the insulator-stack $D$-dot monitor, respectively. Typical measurements obtained with the diagnostic system are presented in Sec. VI. Suggestions for future work are discussed in Sec. VII.

The appendices address some issues in greater detail. All the monitors described herein are located tens of meters from a common double-wall screen room that contains the digital oscilloscopes that record the monitor signals. Hence, the signals suffer a significant degradation in bandwidth due to the long coaxial cables that connect the monitors to the screen room. To correct the degradation, we use the numerical cable-compensation algorithm developed by Boyer [79], as discussed in Appendix A. The bandwidth of a typical monitor system (after cable compensation) is estimated in Appendix B. Systematic and random errors of a typical monitor are listed in Appendix C.

Part of each monitor's coaxial-cable system is located in an intense hard-x-ray-radiation environment. Compton-effect interactions between the $\mathrm{x}$ rays and the electrons in a monitor's coaxial cables induce a current in the cables. The current signal is common to both cables. (This common-mode signal is sometimes referred to as "Compton drive.") This and other common-mode signals are reduced as discussed in Appendix D.

\section{MONITOR LOCATIONS}

Figure 1 presents a cross-sectional view of the four-level $Z$-accelerator stack-MITL system, which constitutes the vacuum-power-flow section of $Z[1,2,4-9]$. As indicated by the figure, the four levels are labeled A, B, C, and D. The four insulator stacks are electrically in parallel; these are connected to the four outer MITLs, which are also in parallel. The currents flowing in the outer MITLs are combined by the double-post-hole vacuum convolute [14-20]. The convolute includes 12-upper and 12-lower posts that connect the outer-MITL anodes together; the posts are equally spaced on a $7.62-\mathrm{cm}$ radius. The convolute also connects together the outer-MITL cathodes. The combined current is delivered from the convolute to the load by the inner MITL.

A total of 12 current and 24 voltage monitors are located in the three insulator-stack anode-electrode rings illustrated by Fig. 1. The monitors are located $165 \mathrm{~cm}$ from the central axis of the accelerator. The upper and lower anode rings each have nine holes in which the monitors are located; the holes are equally spaced azimuthally (separated by $40^{\circ}$ ). There are 18 monitor holes in the middle stack-anode ring, nine that face the ring's top surface (which is the anode surface of B level) and nine that face the bottom (the anode surface of $\mathrm{C}$ level). These holes are also equally spaced azimuthally.

A total of three current and six voltage monitors are fielded in the upper stack-anode ring to measure the current and voltage, respectively, at the A-level insulator stack. The current monitors are located azimuthally at $60^{\circ}, 180^{\circ}$, and $300^{\circ}$ (from north, which is arbitrarily labeled as $0^{\circ}$ ); the voltage monitors are located at $20^{\circ}, 100^{\circ}, 140^{\circ}, 220^{\circ}$, $260^{\circ}$, and $340^{\circ}$. Similarly three current and six voltage monitors are located in the upper half of the middle anode ring to monitor the B-level stack, in the lower half of the middle ring to monitor level $\mathrm{C}$, and in the lower anode ring to monitor level D.

A total of $24 B$-dot monitors are located in the outerMITL anodes, six in each of the four anodes. These monitors are located $80 \mathrm{~cm}$ from the axis of the accelerator. The monitors are located at $60^{\circ}, 100^{\circ}, 180^{\circ}, 220^{\circ}, 300^{\circ}$, and $340^{\circ}$ on each level.

The inner-MITL $B$-dot monitors are located $6 \mathrm{~cm}$ from the axis of the load. Each such monitor is aligned azimuthally with one of the 12 upper posts of the double-posthole convolute, so that the posts can shield (to some extent) the $B$-dots from flow electrons generated in the outer MITLs. (We observe less electron damage to the innerMITL anode in the regions immediately downstream of the posts than to nearby areas. The spatial distribution of the damage is consistent with electron-energy-deposition cal- 
culations presented by Fig. 6 of Ref. [16] and Fig. 9 of Ref. [18].) Hence, each inner-MITL $B$-dot is located at one of 12 possible azimuthal locations. The actual locations are determined by the presence of other experimental hardware located near the load, and vary from shot to shot.

\section{DIFFERENTIAL-OUTPUT INSULATOR-STACK AND OUTER-MITL CURRENT MONITORS}

\section{A. Current-monitor design}

The designs of the insulator-stack and outer-MITL $B$-dot current monitors are essentially identical except for the outer dimensions of the monitor bodies, which differ for reasons having to do with installation and space constraints. Hence we describe here only the specific design of the outer-MITL current monitor.

Two different views of the outer-MITL monitor are presented by Fig. 2. As indicated by the figure, the monitor consists of two $B$-dot sensors separately located in two adjacent cavities in the monitor's body. The body is fabricated from either half-hard or aluminum-oxide-dispersion-hardened copper. The cavity that encloses each sensor is filled with Hysol 4143 silica-filled epoxy with 3404 hardener. The epoxy is vacuum potted. A $0.005-\mathrm{mm}-$ thick nichrome film is placed over the epoxy; the film allows the magnetic field to penetrate to the sensors, but shields the epoxy and sensors from the electric field in the MITL, which can reach megavolts per centimeter.

Each sensor consists of four 3-mm-diameter wire loops that are electrically in series; these are wound using a single continuous piece of copper wire. The wire is 26 gauge, has a nominal diameter of $0.404 \mathrm{~mm}$, and is coated with Formvar (which provides electrical insulation) [80]. The total outer diameter of the copper wire including the Formvar insulation is $0.452 \mathrm{~mm}$; hence, the Formvar coating is approximately $0.024 \mathrm{~mm}$ thick. For each sensor, one end of the wire is connected to the outer conductor of a 17.9-mm-length section of 3.6-mm-diameter semirigid coaxial cable, as shown by Fig. 2. The other end of the wire connects to the inner conductor of the coax. Both connections are established by soldering.

The outer surface of the semirigid coax's outer conductor is silver epoxied (using Tra-Duct 2902, manufactured by Tra-Con [81]) to the copper body. As suggested by Fig. 2, the coax is electrically connected to a subminiature-version-A (SMA) barrel connector. The SMA barrel is screwed into a threaded hole in the copper body. The threads of the SMA barrel are coated with silver epoxy to improve the electrical and mechanical integrity of the connection between the barrel and body. When the monitor is correctly assembled, the total series resistance of the $B$-dot sensor (as measured across the output end of the SMA connector) is $\leq 20 \mathrm{~m} \Omega$. If the resistance is greater than this value, the monitor is not used.

The two $B$-dot sensors of each $B$-dot current monitor are designed to produce opposite-polarity signals for commonmode-noise rejection [21]. Two matched-length 2.2-mmdiameter $50-\Omega$ conformable coaxial cables (type RG-405) connect the monitor's two SMA barrel connectors to a $50-\Omega$ balun [82].

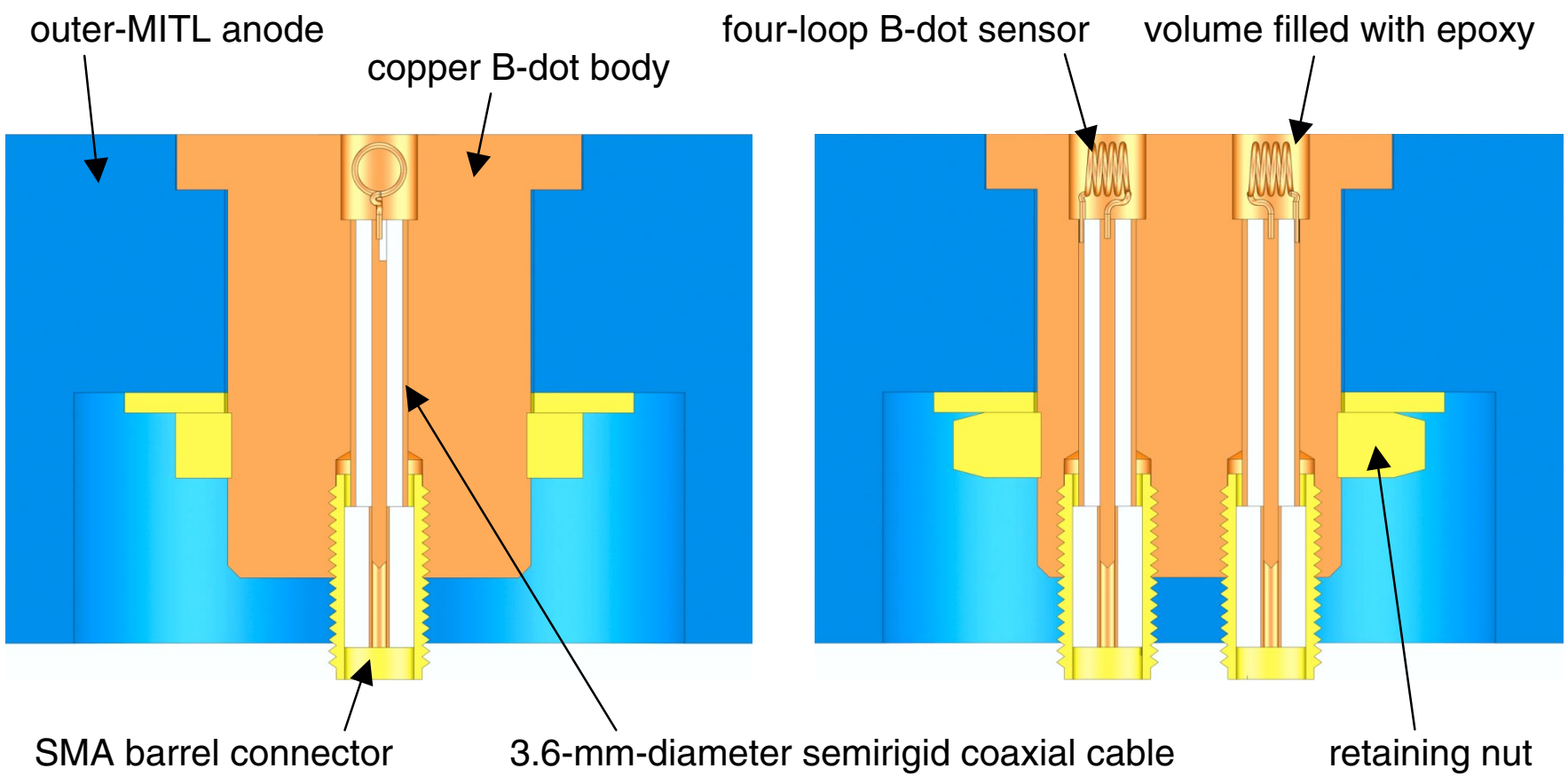

FIG. 2. (Color) Two cross-sectional views of the differential-output $B$-dot current monitor that is fielded on the outer MITLs of the $Z$ accelerator. Not shown here is the $0.005-\mathrm{mm}$-thick nichrome foil that is placed over the epoxy-filled volumes. The foil shields the epoxy and $B$-dot sensors from the high electric field in the MITL's anode-cathode gap. 
The balun is a device that has two 50-ohm inputs and one 50 -ohm output. The balun attenuates each input signal by a factor of 2 , inverts one of the two signals, then adds it to the other. The sum is delivered to the balun's output. Hence, the balun cancels - to first-order-common-mode signals. The balun used is a Prodyn model BIB-100B (mod); the "mod" designation identifies the unit as a mechanically ruggedized version (i.e., a "modified" version) of the standard BIB-100B. The balun has a $15 \mathrm{kHz}-$ $400 \mathrm{MHz} 3-\mathrm{dB}$ bandwidth. The common-mode-rejection ratio is $<-30 \mathrm{~dB}$ for frequencies $<1 \mathrm{GHz}$, and $<-50 \mathrm{~dB}$ for frequencies $<10 \mathrm{MHz}$.

The RG-405 cable provides reasonable bandwidth $(0.49 \mathrm{~dB} / \mathrm{m}$ at $500 \mathrm{MHz})$ while producing an acceptable level of Compton drive, which is generated by the bremsstrahlung field of the $Z$ accelerator [83,84]. The length of the two RG-405 cables is just long enough to permit locating the balun outside the most-intense bremsstrahlung environment of the accelerator. Cancellation by the balun of common-mode Compton signals is discussed in Appendix D.

On a typical $Z$ shot, the peak total voltage (which is primarily due to the current being measured) produced by one of the two $B$-dot sensors in an outer-MITL $B$-dot monitor is on the order of $100 \mathrm{~V}$. Since the balun attenuates the signal produced by each sensor a factor of 2 , inverts one of the two signals, then adds it to the other, the amplitude of the combined signal at the output of the balun is again $\sim 100 \mathrm{~V}$. A long (35-80 m) coaxial cable (which consists of several cable sections connected in series) transmits the balun-output signal to a double-wall screen room.

Inside the screen room, the signal's amplitude is reduced by high-voltage $(\geq 1 \mathrm{kV}$ ) high-bandwidth $(\geq 4 \mathrm{GHz})$ $50-\Omega$ attenuators $[85,86]$ before the signal is recorded on a Tektronix $0.5 \mathrm{~ns} /$ sample digitizing oscilloscope [87]. The oscilloscope records the signal with a long baseline ( $>500$ sample points) to permit an accurate determination of the baseline-voltage level; i.e., the approximately dc component of the voltage measured by the oscilloscope before the arrival of the $B$-dot signal.

Because the cable connecting the balun output to the screen-room is long $(35-80 \mathrm{~m})$, the recorded signal incurs significant high-frequency degradation. A post-shot numerical procedure [79] is applied to the recorded $B$-dot data to compensate for cable losses, as discussed in Appendix A. After cable compensation, the baseline voltage is measured, then subtracted from the signal. The signal is subsequently numerically integrated to reconstruct the MITL current, as discussed in Sec. III B.

We integrate the signals numerically, instead of using a passive $R C$ integrating circuit (as is sometimes done), for the following reasons: (i) An integrating circuit has stray inductances and capacitances that give the circuit resonant frequencies, which artificially add high-frequency components to the signal; (ii) the impedance of such a circuit is not exactly $50 \Omega$, and the impedance is frequency dependant; hence, such a circuit reflects part of the incoming signal, and the reflection coefficient is frequency dependent; (iii) an integrating circuit needs to be calibrated to determine its effective $R C$ time constant for pulses of interest; (iv) the calibrations drift over time; and (v) since an $R C$ circuit only integrates over time scales much less than $R C$, the integrated signal needs to be numerically droop corrected for many situations of practical interest. Moreover, $R C$ integrating circuits are usually calibrated using numerical integration as a reference standard. Hence, it would appear that numerically integrating a $B$-dot signal directly is more accurate than using an integrating circuit that is, in turn, calibrated using numerical integration.

\section{B. B-dot-sensor circuit model}

A circuit model of each of the two $B$-dot sensors in an outer-MITL $B$-dot monitor is used to reconstruct the MITL current from the monitor-output signal. To a reasonable approximation the outer-MITL $B$-dot sensor described in this article can be modeled as indicated by Fig. 3. (The same model is also used for the $B$-dot sensors of the insulator-stack and inner-MITL current monitors.)

The model presented by Fig. 3 consists of three elements: the mutual inductance $M$ between the outer-MITL being monitored and the $B$-dot sensor, the self-inductance $L$ of the $B$-dot sensor's wire coil, and the impedance $Z$ of the monitor's output cable. (The cable impedance is the same as that of the balun, attenuators, and digitizer that

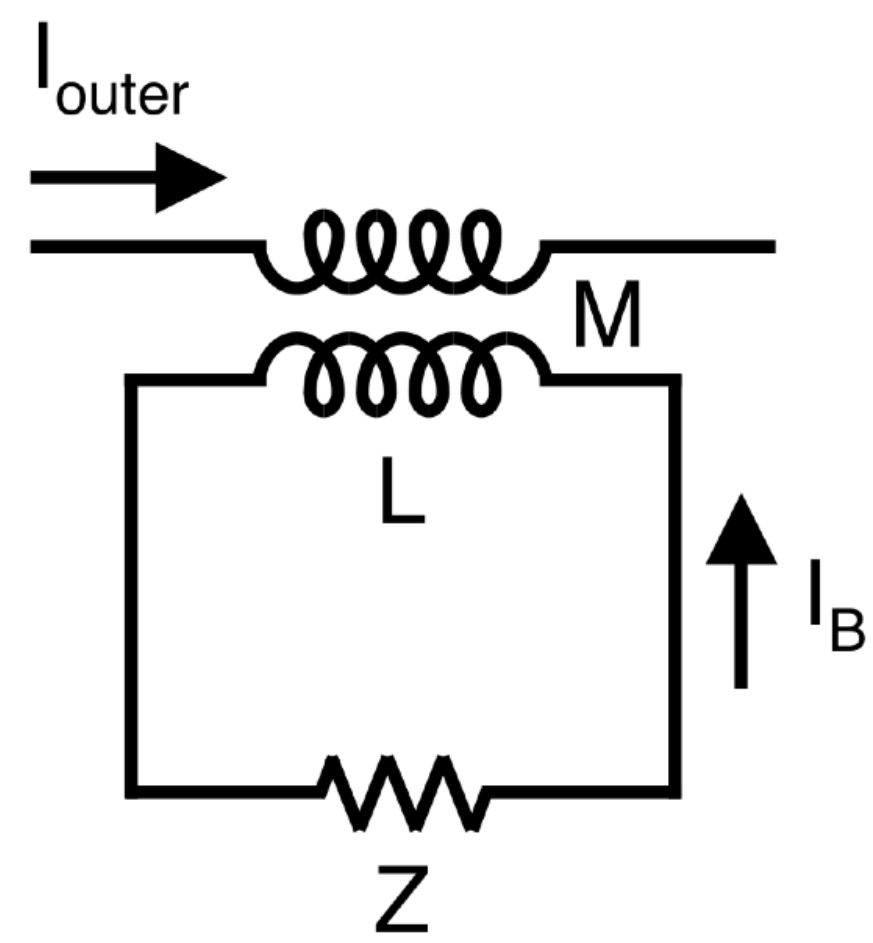

FIG. 3. Lumped-circuit model of a single outer-MITL $B$-dot current sensor. 
records the $B$-dot signal.) The model suggests that

$$
M \frac{d I_{\text {outer }}}{d t}=L \frac{d I_{B}}{d t}+Z I_{B}
$$

where $I_{\text {outer }}$ is the outer-MITL current and $I_{B}$ is the current flowing in the $B$-dot circuit. Since a $50-\Omega$ data-recording system is used,

$$
Z=50 \Omega \text {. }
$$

The $B$-dot-sensor's output voltage $V_{B}$ can be expressed as

$$
V_{B}=I_{B} Z
$$

hence, combining Eqs. (1) and (3) gives

$$
I_{\text {outer }}=\frac{1}{M}\left(\frac{L}{Z} V_{B}+\int_{0}^{t} V_{B} d t\right)
$$

When for time periods of interest the first term on the right-hand side of Eq. (4) is much greater than the second, the current sensor's output voltage $V_{B}$ is approximately proportional to $I_{\text {outer. }}$. In this limit the sensor is said to be self-integrating $[24,25,27,58]$. When the first term is much less than the second, the sensor's output voltage is approximately proportional to $d I_{\text {outer }} / d t$, and the sensor is said to be differentiating $[24,25,27,58]$.

Historically, $B$-dot monitors have been designed to operate in either of these two limits. The monitors described herein are designed to be differentiating. However, when desired, modern data-recording systems and computational resources make it straightforward to use both terms on the right-hand side of Eq. (4) to infer $I_{\text {outer }}$ from $V_{B}$.

For the stack and outer-MITL $B$-dot sensors described herein, calculations and measurements indicate $L=$ $40 \mathrm{nH}$. Since $L / Z=0.8 \mathrm{~ns}$, the first term on the righthand side of Eq. (4) can be neglected for the 100-ns power pulses of interest; hence, to a good approximation

$$
I_{\text {outer }}=\frac{1}{M} \int_{0}^{t} V_{B} d t
$$

When Eq. (5) is used to reconstruct $I_{\text {outer }}$, Eq. (4) predicts that the $10 \%-90 \%$ rise time of the $B$-dot sensor is given by

$$
\tau_{10 \%-90 \%}=2.2 \frac{L}{Z} .
$$

Of course, the rise time could be reduced significantly by using Eq. (4) instead of Eq. (5) to reconstruct $I_{\text {outer }}$. In principle, if Eq. (4) were an exact model of a $B$-dot sensor, and the exact values of $L$ and $Z$ were known, then using Eq. (4) to reconstruct $I_{\text {outer }}$ would provide a sensor with infinite bandwidth. However, Eq. (4) is a lumped-circuit model that ignores transmission-line effects that, in practice, limit the bandwidth. (Moreover, the total diagnosticsystem bandwidth is limited in part by that of the datarecording system.)
Equations (1), (4), and (5) account neither for effects due to penetration of magnetic flux into the walls of the copper aperture of the cavity surrounding the $B$-dot coil, nor to penetration of flux into the wire used to form the coil itself. Both effects increase the sensitivity of the $B$-dot with time; i.e., both cause $M$ to increase at lower frequencies. Hence, the $B$-dot monitor behaves approximately as if its signal $V_{B}$ were transmitted through a high-pass $R C$ filter with a negative $R C$ time constant, so that high-frequency components are unchanged, but lower frequencies are amplified.

Motivated by this observation, we make a first-order correction for such time-dependent skin-depth effects by using, instead of Eq. (5), the following expression:

$$
I_{\text {outer }}=\frac{\exp \left(-t / \tau_{f}\right)}{M} \int_{0}^{t} V_{B} \exp \left(\frac{t}{\tau_{f}}\right) d t,
$$

where $\tau_{f}$ is a characteristic flux-penetration time. Equation (7) applies to the function $I_{\text {outer }}$ [as given by Eq. (5)] a numerical filter that leaves high frequencies unchanged, but attenuates lower frequencies. Equation (7) is analogous to the well-known expression that is applicable to a high-pass $R C$ filter with a positive time constant. The time constant of the analogous $R C$ filter is $\tau_{f}$. For times $t \ll \tau_{f}$, Eq. (7) reduces to Eq. (5).

Equation (7) can also be obtained as follows. When $M$ is not constant in time, Eq. (5) can be expressed as

$$
\frac{d\left(M I_{\text {outer }}\right)}{d t}=V_{B} .
$$

We assume $M$ does not change significantly with time for time durations of interest. We also assume $d M / d t$ can be approximated as follows:

$$
\frac{d M}{d t} \sim \frac{M}{\tau_{f}} .
$$

Combining Eqs. (8) and (9) gives

$$
\frac{d I_{\text {outer }}}{d t}+\frac{I_{\text {outer }}}{\tau_{f}}=\frac{V_{B}}{M} .
$$

The solution of Eq. (10) is given by Eq. (7).

The outer-MITL current $I_{\text {outer }}$ is reconstructed from $V_{B}$ using Eq. (7). The quantities $M$ and $\tau_{f}$ are estimated using the calibration procedure outlined in Sec. III C. The calibration procedure assumes an equation similar to Eq. (7), and finds that for the outer-MITL $B$-dot, $\tau_{f} \sim 2.55 \mu \mathrm{s} .\left(\tau_{f}\right.$ is also approximately $2.55 \mu \mathrm{s}$ for the insulator-stack $B$-dot.) Hence when the current rises to its peak value in $100 \mathrm{~ns}$, the flux-penetration correction performed by Eq. (7) is $\sim 3 \%$ at peak current.

We note that the balun used by the outer-MITL and insulator-stack $B$-dot monitors includes two ferromagnetic cores that have a volt-second product of $5 \times 10^{-5}$. The flux-penetration correction discussed above implicitly accounts for the small signal droop caused by the balun's 


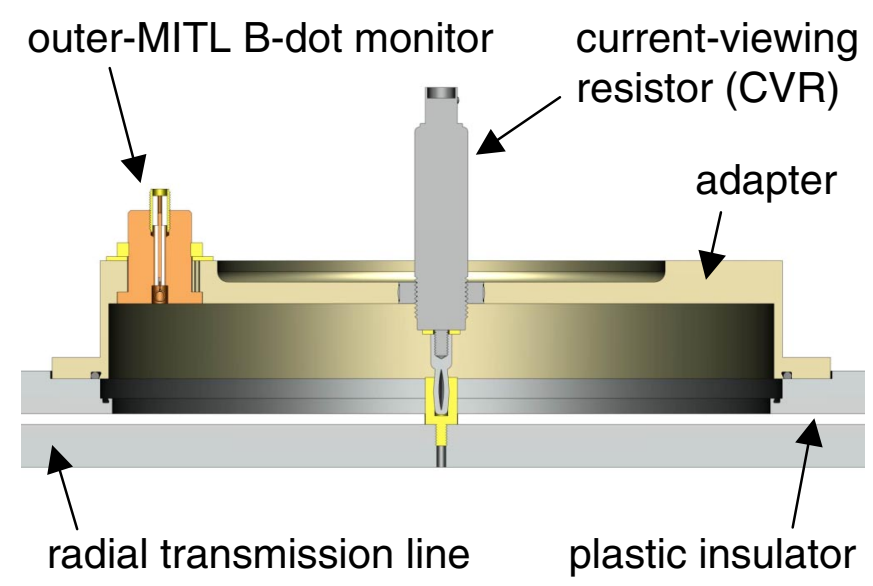

FIG. 4. (Color) Cross-sectional view of the central region of the $B$-dot calibration system.

cores, since the calibration of a monitor is performed with the same balun that is fielded with the monitor on the accelerator.

\section{Current-monitor calibrations}

This section describes the calibration of the outer-MITL $B$-dot current monitors. Similar calibration procedures are used for the insulator-stack and inner-MITL $B$-dots.

The outer-MITL $B$-dots are calibrated using a radial transmission line that is driven by an azimuthally symmetric current pulse. The reference current against which the $B$-dots are calibrated is obtained using a current-viewing resistor (CVR). The central region of the calibration system is illustrated by Fig. 4. The adapter geometry near the $B$-dot monitor is designed to be effectively the same as that of the outer MITL near the monitor when it is fielded on the MITL. (The adapters used to calibrate the insulator-stack and inner-MITL $B$-dots differ from that illustrated by Fig. 4.)

The calibration system's radial transmission line is $76 \mathrm{~cm}$ in diameter. The radial line is driven by $4831-\Omega$ Reynolds high-voltage coaxial cables (Reynolds part number 167-2669) [88] that are attached at 48 equally spaced azimuthal locations along the radial line's outer circumference. The cables in turn are driven by a 10-kA pulse generator.

The pulse generator consists of a single 40-kV 100-nF 15-nH capacitor, an inductor, a switch, and the 48 coaxial cables. The capacitor serves as the initial energy source for the pulser. The high-voltage electrode of the capacitor connects to the inductor, which consists of a 10-cm-wide metal sheet. The sheet in turn connects to a mechanical switch that consists of two stainless-steel electrodes submerged in Flourinert (a high-dielectric-strength fluid). The output of the switch is connected to a $10-\mathrm{cm}$-wide electrode, to which are attached the 48 inner conductors of the coaxial cables. The 48 outer conductors are connected to the ground electrode of the capacitor. The initial charge voltage on the capacitor is on the order of $10 \mathrm{kV}$.

The capacitance of the capacitor, total system inductance, and length of the 48 cables are selected to produce a current-pulse shape similar to that of the $Z$ accelerator. The CVR is a 5-m $\Omega$ T\&M Research CVR (model SSMA-2005) [89], and is mounted at the center of the radial transmission line.

The calibrations are performed assuming an expression similar to Eq. (7):

$$
I_{\mathrm{cal}}=\frac{\exp \left(-t / \tau_{f}\right)}{M_{\mathrm{cal}}} \int_{0}^{t} V_{B} \exp \left(\frac{t}{\tau_{f}}\right) d t
$$

where $I_{\text {cal }}$ is the current flowing in the calibration system's transmission line, and $M_{\text {cal }}$ is the mutual inductance between the transmission line and the $B$-dot sensor. The calibrations neglect variations in $M_{\text {cal }}, \tau_{f}, L$, and $Z$ with temperature, voltage, etc.

We calibrate an outer-MITL $B$-dot monitor by minimizing the normalized standard deviation of the pointwise difference $\sigma_{n}$ [90] between the calibration-system current $I_{\text {cal }}$, as calculated by Eq. (11), and the calibration-system current $I_{\mathrm{CVR}}$, as measured by the CVR. We define $\sigma_{n}$ as follows:

$$
\sigma_{n} \equiv \frac{1}{I_{\mathrm{CVR}, \text { peak }}}\left(\frac{1}{N-1} \sum_{i=1}^{N}\left[I_{\mathrm{cal}}\left(t_{i}\right)-I_{\mathrm{CVR}}\left(t_{i}\right)\right]^{2}\right)^{1 / 2},
$$

where $N$ is the number of samples in the time history. The calibration procedure consists of finding the values of $M_{\text {cal }}$ and $\tau_{f}$ that minimize $\sigma_{n}$. A typical calibration result is

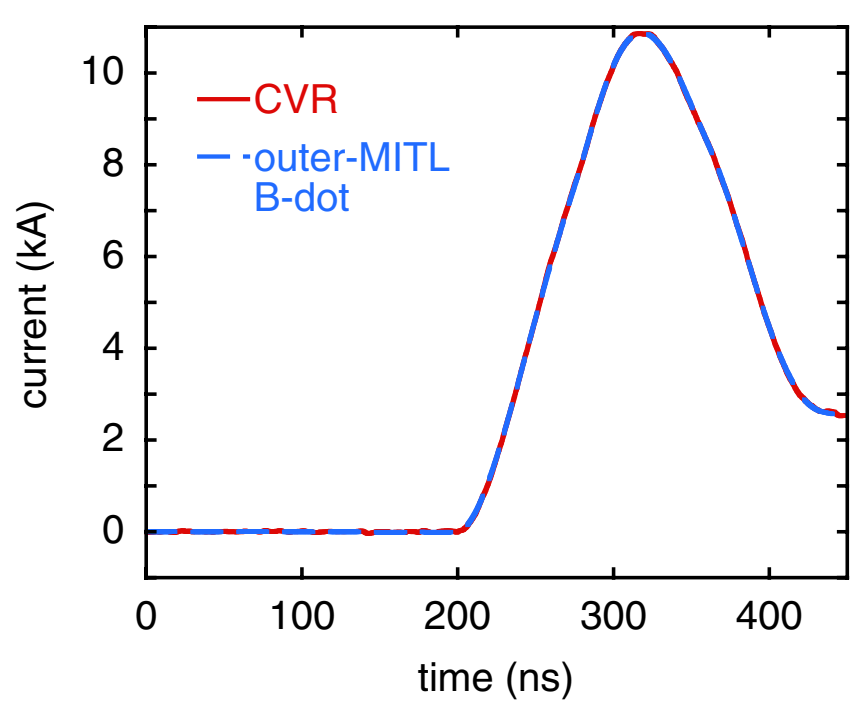

FIG. 5. (Color) Result of the calibration of an outer-MITL $B$-dot current monitor. The reference current is that measured by a current-viewing resistor (CVR). The normalized standard deviation of the pointwise difference [Eq. (12)] between the two current-pulse shapes is less than $1 \%$. 
presented by Fig. 5; $\sigma_{n}$ for the two traces shown is less than $1 \%$.

Since the calibration-system transmission line and the accelerator's outer MITLs are approximately axisymmetric,

$$
M=M_{\text {cal }} \frac{r_{\text {cal }}}{r} .
$$

The quantity $r_{\text {cal }}$ is the radial distance of the monitor (when it is installed on the calibration system) from the central axis of the calibrator's transmission line, and $r$ is the radial distance of the monitor (when it is installed on an outer MITL) from the central axis of the accelerator.

The sensitivity of an outer-MITL $B$-dot monitor is nominally $1.3 \times 10^{-12} \mathrm{~V} \mathrm{~s} \mathrm{~A}^{-1}$. As discussed above, for a typical $Z$-accelerator shot, the peak output voltage (during the main power pulse) of an outer-MITL monitor is $\sim 100 \mathrm{~V}$. Because the insulator-stack $B$-dots are located a factor of 2 further from the axis of the accelerator, their sensitivity is a factor of 2 lower, and their peak output voltage is $\sim 50 \mathrm{~V}$.

\section{INNER-MITL CURRENT MONITOR}

\section{A. Current-monitor design}

The design of an inner-MITL $B$-dot current monitor is outlined by Fig. 6 . The monitor is located at the same azimuthal location as that of an upper convolute post. As discussed in Sec. II, the post assists in shielding the monitor from electrons launched in the outer MITLs, which are upstream of the convolute. The monitor is fabricated using many of the same materials and techniques described in Sec. III A. Differences between the inner-MITL monitor and that described in Sec. III A are summarized below.

Because of space constraints, the inner-MITL monitor includes a single $B$-dot sensor. Hence each inner-MITL monitor is by itself not a differential-output monitor, since it generates only one signal. (Of course, such a monitor is still "differential" in the sense that it measures the time derivative of the magnetic field.) However, two innerMITL monitors are fielded-with opposite polarities to reduce common-mode noise. (Consequently, a pair of opposite-polarity inner-MITL monitors could be considered as a single differential-output monitor.) Each $B$-dot sensor consists of a single loop of copper wire; the inner diameter of the loop is $1.27 \mathrm{~mm}$. The sensor is not potted in epoxy or any other material. The two leads that connect the sensor to the semirigid coaxial cable shown in Fig. 6 are twisted to minimize the contribution of the leads to the sensitivity.

The sensor is located in a cylindrical copper cavity that has an inside diameter of $9.04 \mathrm{~mm}$. The center of the sensor is recessed $5.61 \mathrm{~mm}$ above the inner-MITL-anode surface, which reduces damage to the sensor caused by the MITL flow electrons. The aperture in the copper cavity through which the magnetic field is coupled to the sensor is $5.08 \mathrm{~mm}$ in diameter and 2.54-mm thick.

After an inner-MITL $B$-dot signal is attenuated, recorded, and numerically cable compensated [79], the baseline-voltage level is measured and subtracted from the signal. The signal is subsequently numerically integrated using the process described in Sec. III B. We integrate numerically, instead of using a passive $R C$ integrating circuit, for the reasons discussed in the last paragraph of Sec. III A.

After signals from the two inner-MITL $B$-dot monitors have been integrated, one of the two signals is inverted (since the two monitors have opposite polarities), and added to the other to reduce common-mode noise. After the sum is divided by 2 , it is reduced $3 \%$ to correct for the proximity of the $B$-dot monitors to the convolute posts, which affect the symmetry of the magnetic field at the monitor location. This geometric correction is suggested

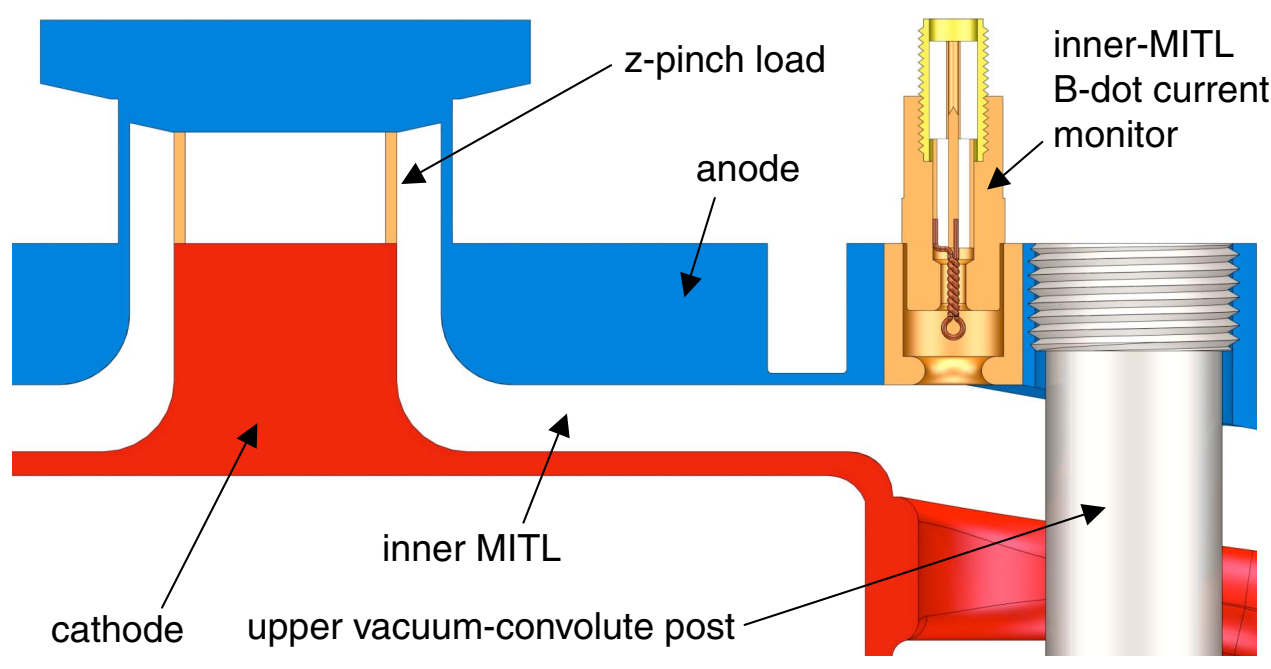

FIG. 6. (Color) Cross-sectional view of the inner-MITL $B$-dot current monitor. 


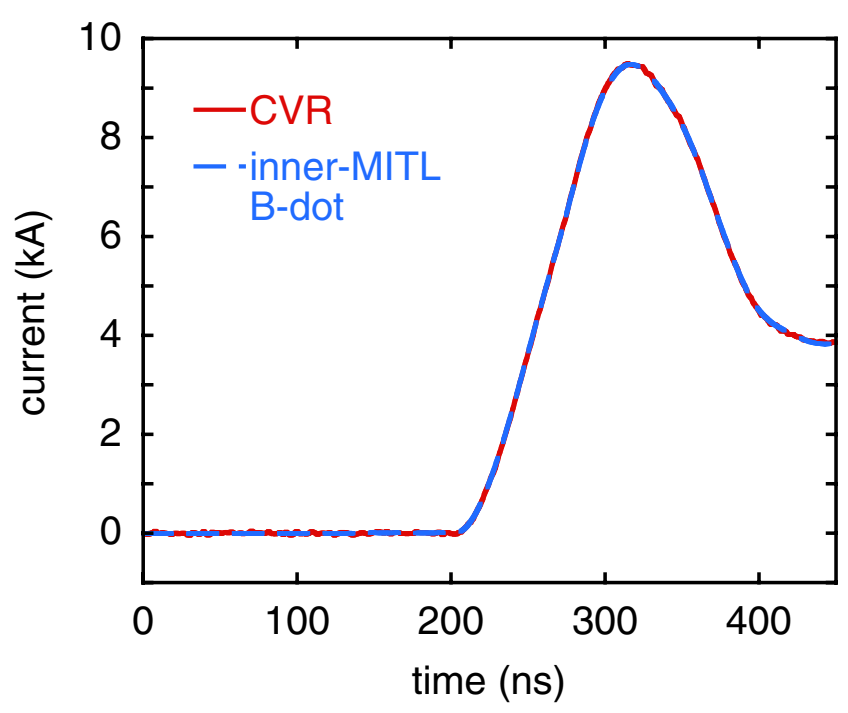

FIG. 7. (Color) Result of the calibration of an inner-MITL $B$-dot current monitor. The reference current is that measured by a current-viewing resistor (CVR). The normalized standard deviation of the pointwise difference [Eq. (12)] between the two current-pulse shapes is less than $1 \%$.

by double-post-hole-convolute simulations performed by Hughes and Clark using the 3D electromagnetic code LSP [15].

\section{B. B-dot-sensor circuit model}

The circuit model used to reconstruct the inner-MITL current from the output voltage of an inner-MITL $B$-dot monitor is identical to that described in Sec. III B; the equation used is Eq. (7). The flux-penetration time $\tau_{f}$ for a typical inner-MITL monitor is on the order of $2 \mu \mathrm{s}$.

\section{Current-monitor calibration}

The inner-MITL $B$-dot current monitors are calibrated using the system described in Sec. III C. A typical calibration result is presented by Fig. 7. The normalized standard deviation of the pointwise difference $\sigma_{n}$ [Eq. (12)] between the $B$-dot and CVR current-pulse shapes is less than $1 \%$. The sensitivity of an inner-MITL $B$-dot is nominally $2 \times 10^{-13} \mathrm{~V} \mathrm{~s} \mathrm{~A}^{-1}$. On a typical $Z$-accelerator shot, the peak output voltage of this monitor is $\sim 100 \mathrm{~V}$.

\section{DIFFERENTIAL-OUTPUT INSULATOR-STACK VOLTAGE MONITOR}

\section{A. Voltage-monitor design}

The insulator-stack $D$-dot voltage monitors are mounted in the stack-anode rings as indicated by Figs. 1 and 8. Each of the $24 \mathrm{D}$-dot monitors is located at the same radial distance from the central axis of the accelerator, between the anode triple junction of a stack insulator ring and an Oring groove. (The O-ring grooves are not shown in the figures.) Two-dimensional electrostatic calculations per-

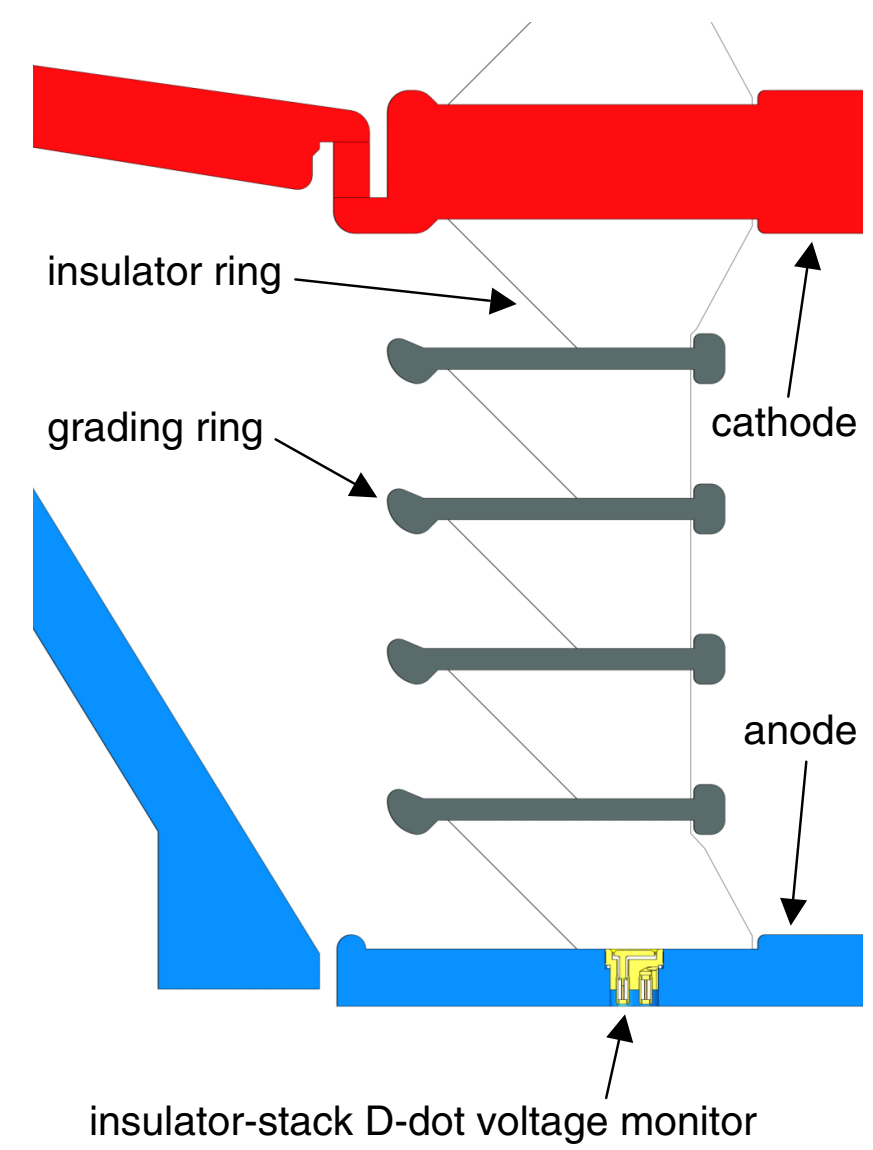

FIG. 8. (Color) Location of a differential-output $D$-dot voltage monitor in the anode of the $Z$-accelerator's B-level insulator stack. (All four stack levels are illustrated by Fig. 1.)

formed with the ELECTRO code [91] (a boundary-element-method electric-field solver) demonstrate that the perturbation due to the monitors of the electric field at the vacuum-insulator interface is negligible.

The $D$-dot-monitor design is detailed by Fig. 9. The outer diameter of the displacement-current sensor is $1.8 \mathrm{~cm}$. The current-contact gasket is fabricated by Tyco Electronics (AMP part number 192045-5) [92]; the gasket is 5.08-mm wide and is fabricated from a beryllium-copper sheet that is $0.127-\mathrm{mm}$ thick. Both the displacementcurrent sensor and the $D$-dot monitor body are fabricated from brass. The sensor is potted in Stycast epoxy that is cured under vacuum; Hysol epoxy is also used.

As indicated by Fig. 9, one of the monitor's two SMA barrels is connected to the displacement-current sensor. The other terminates in an electromagnetic shield (which is an open-circuit termination) to provide a null measurement. The shield is penetrated by a small hole to allow trapped air to be evacuated when the monitor is placed in a vacuum environment. The two outputs are connected to a balun for common-mode-noise reduction.

The balun's output signal is attenuated, recorded, and numerically cable compensated [79]. After cable compen- 


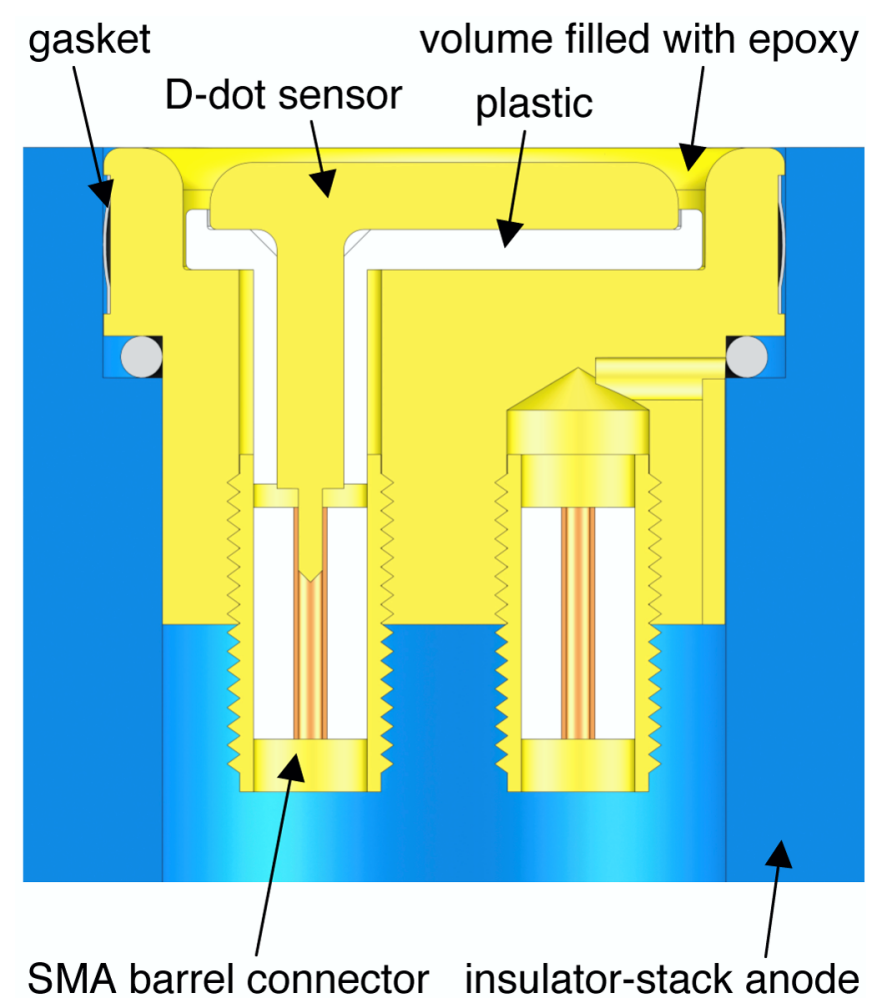

FIG. 9. (Color) Cross-sectional view of the differential-output $D$-dot voltage monitor that is fielded on the insulator stack of the $Z$ accelerator.

sation, the baseline voltage is measured, then subtracted from the signal. The signal is subsequently numerically integrated to reconstruct the insulator-stack voltage, as discussed in Sec. V B. We integrate the signal numerically, instead of using a passive $R C$ integrating circuit, for the reasons discussed in the last paragraph of Sec. III A.

\section{B. $\boldsymbol{D}$-dot-sensor circuit model}

A lumped-circuit model of the $D$-dot sensor is used to reconstruct the stack voltage from the output voltage of the monitor [75]. To a reasonable approximation the $D$-dot sensor can be modeled as indicated by Fig. 10. The model consists of three elements [75]: the capacitance $C_{D}$ between the $D$-dot sensor and the electrode opposite the sensor, the capacitance $C_{\text {stray }}$ between the sensor and the surrounding anode electrode, and the impedance $Z$ of the $D$-dot-monitor output cable. (The cable impedance is the same as that of the balun, attenuators, and digitizer that records the $D$-dot signal.)

An insulator stack of a pulsed-power accelerator typically includes several insulator rings connected in series. As suggested by Figs. 1 and 8, the stack $D$-dot monitor described herein directly measures the voltage across a single insulator ring, which is the ring in contact with the monitor. Assuming the circuit model given by Fig. 10, the voltage across the ring $V_{\text {ring }}$ is estimated as follows [75]:

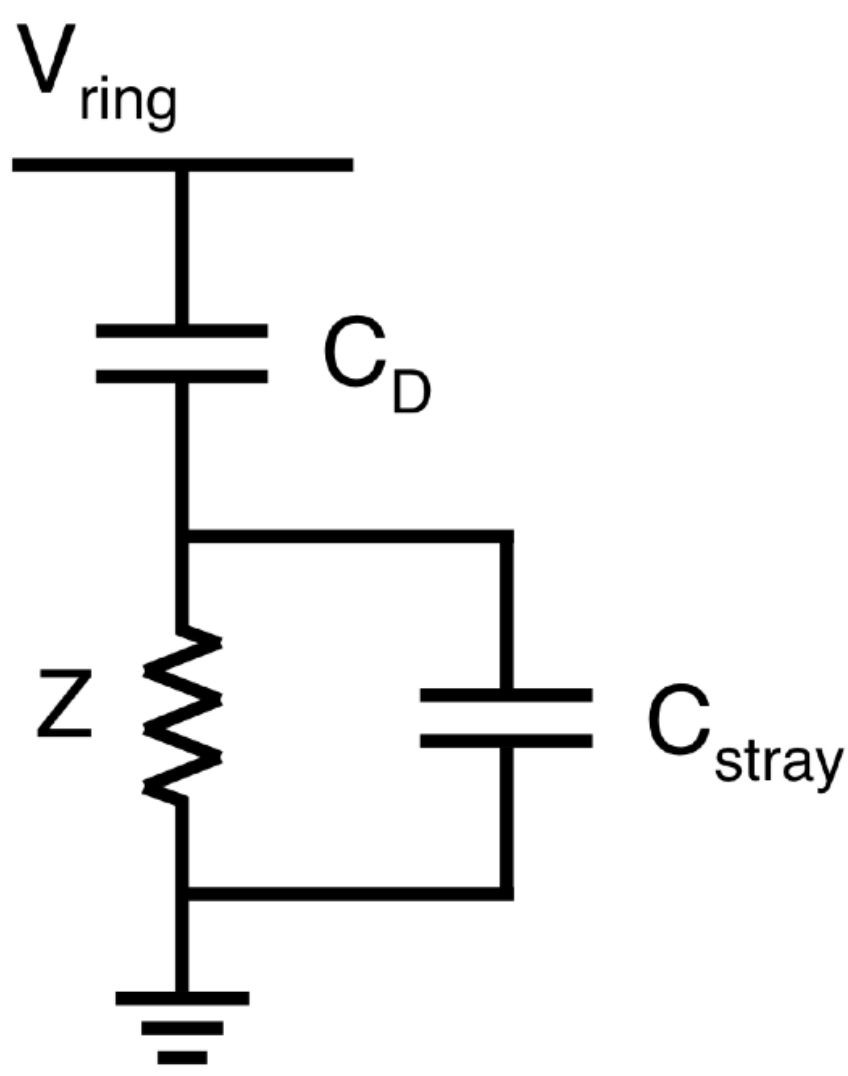

FIG. 10. Lumped-circuit model of an insulator-stack $D$-dot sensor [75].

$$
V_{\text {ring }}=\left(\frac{C_{D}+C_{\text {stray }}}{C_{D}}\right) V_{D}+\frac{1}{Z C_{D}} \int_{0}^{t} V_{D} d t
$$

where $Z$ is given by Eq. (2), and $V_{D}$ is the output voltage of the $D$-dot sensor. The voltage across an entire multiring insulator stack $V_{\text {stack }}$ is approximately proportional to $V_{\text {ring }}$ :

$$
V_{\text {stack }}=k V_{\text {ring }} \text {. }
$$

When the voltage across the stack is evenly divided between the rings, the constant $k$ is, of course, equal to the number of rings in the stack.

When for time periods of interest the first term on the right-hand side of Eq. (14) is much greater than the second, the $D$-dot sensor's output voltage $V_{D}$ is approximately

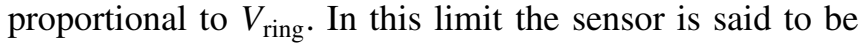
self-integrating [75]. When the first term is much less than the second, the sensor's output voltage is approximately proportional to $d V_{\text {ring }} / d t$, and the sensor is said to be differentiating [75].

Historically, $D$-dot monitors have been designed to operate in either of these two limits. The monitors described herein are designed to be differentiating. However, as discussed in Sec. IIIB, modern data-recording systems 
and computational resources make it straightforward to use both terms on the right-hand side of Eq. (14) to infer $V_{\text {ring }}$ from $V_{D}$.

For the $D$-dot sensors described in this article, we estimate from calculations and measurements that $C_{D}=$ $0.1 \mathrm{pF}$ and $C_{\text {stray }}=12 \mathrm{pF}$; hence $Z\left(C_{D}+C_{\text {stray }}\right)=$ $0.6 \mathrm{~ns}$. Consequently, the first term on the right-hand side of Eq. (14) can be neglected for the 100-ns power-pulses of interest, and Eqs. (14) and (15) can be combined to give

$$
V_{\text {stack }}=\frac{k}{Z C_{D}} \int_{0}^{t} V_{D} d t
$$

Equation (16) can be used with an in situ calibration process to determine the ratio $k / Z C_{D}$ that gives the best match of the inferred stack voltage to the reference voltage used for the calibration.

When Eq. (16) is used to reconstruct $V_{\text {stack }}$, Eq. (14) predicts that the $10 \%-90 \%$ rise time of the $D$-dot sensor is given by

$$
\tau_{10 \%-90 \%}=2.2 Z\left(C_{D}+C_{\text {stray }}\right) \text {. }
$$

Of course, the rise time could be reduced substantially by using Eqs. (14) and (15) instead of Eq. (16) to reconstruct $V_{\text {stack. }}$ In principle, if Eq. (14) were an exact model of a $D$-dot sensor, and the exact values of $C_{\text {stray }}$ and $Z$ were known, then using Eqs. (14) and (15) to reconstruct $V_{\text {stack }}$ would provide infinite bandwidth. However, Eq. (14) is a lumped-circuit model that ignores transmission-line effects that, in practice, limit the bandwidth. (Moreover, the total

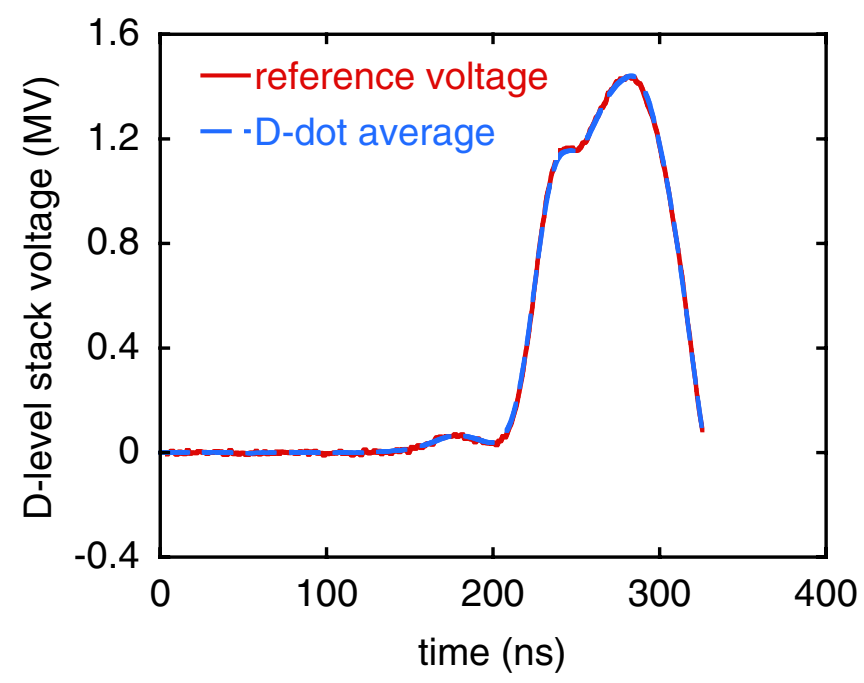

FIG. 11. (Color) Result of an in situ calibration of a differentialoutput $D$-dot voltage monitor. The reference voltage is generated using current measurements (made with calibrated $B$-dot current monitors) and the geometry of the stack-MITL-load system. The normalized standard deviation of the pointwise difference between the two voltage-pulse shapes is less than $1 \%$. The standard deviation is calculated using an expression analogous to Eq. (12).

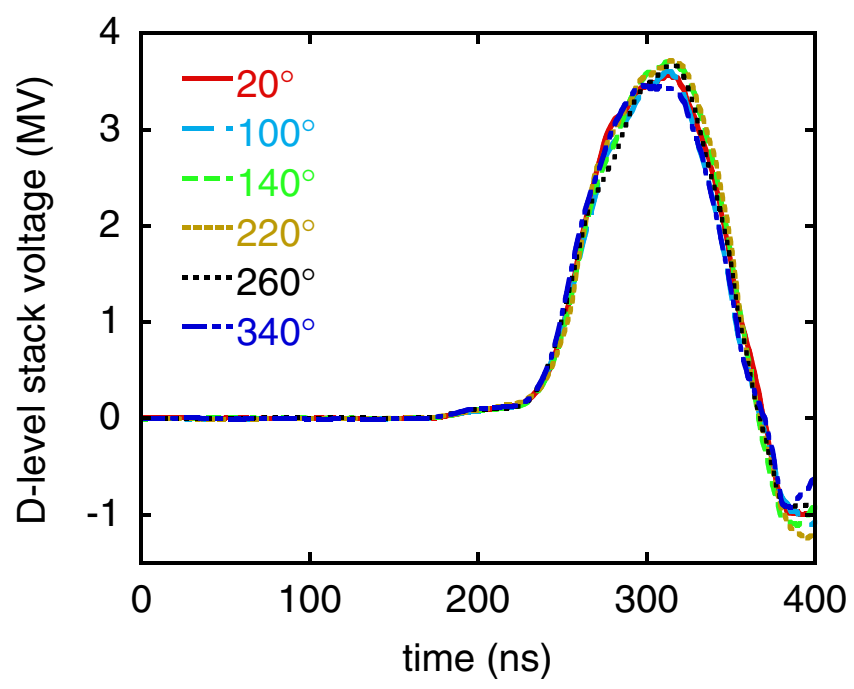

FIG. 12. (Color) Measurements on Z-shot 1548 of the D-level insulator-stack voltage at 6 azimuthal locations.

diagnostic-system bandwidth is limited in part by that of the data-recording system.)

\section{Voltage-monitor calibrations}

Both benchtop and in situ calibrations of the $D$-dot voltage monitors are performed. We describe here only the latter, since these ultimately determine the monitor sensitivities that are used to process data acquired on $Z$-accelerator shots.

The in situ calibrations are performed assuming Eq. (16), and give the ratio $k / Z C_{D}$. The calibrations neglect skin-depth effects, and variations of $C_{D}, C_{\text {stray }}$, and $Z$ with temperature, voltage, etc.

The in situ calibrations are performed by applying a 1.5MV Z-accelerator power pulse to the insulator stack that

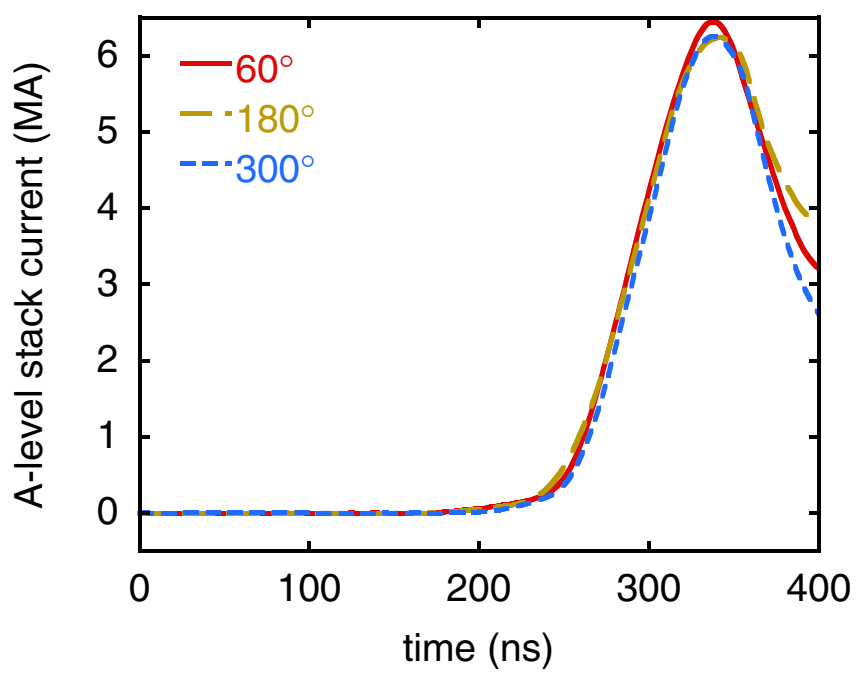

FIG. 13. (Color) Measurements on Z-shot 1548 of the A-level insulator-stack current at 3 azimuthal locations. 
contains the voltage monitors to be calibrated. The stack's corresponding MITL is terminated in a short-circuit load. Faraday's law of induction is used to generate the reference voltage: currents are obtained from the calibrated outerMITL $B$-dot monitors described in Sec. III, and inductances from the insulator-stack, MITL, and load geometries. Figure 11 presents a typical calibration result. The normalized standard deviation of the pointwise difference [90] between the $D$-dot-monitor and reference-voltage pulse shapes is less than $1 \%$. The standard deviation is calculated using an expression analogous to Eq. (12).

The sensitivity of the insulator-stack $D$-dot monitor (when a balun is included in the system) is nominally $1.5 \times$ $10^{-13} \mathrm{~V} \mathrm{~s} \mathrm{~m} \mathrm{~V}^{-1}$. This assumes that the electric field at the $D$-dot sensor is given in units of $\mathrm{V} \mathrm{m}^{-1}$. The A- and B-level insulator stacks of the $Z$ accelerator have an insulator height of $0.29 \mathrm{~m}$; hence, the monitor sensitivity for these two levels can also be expressed as $5.3 \times 10^{-13} \mathrm{~V} \mathrm{~s} \mathrm{~V}^{-1}$. For a typical $Z$-accelerator shot, the peak output voltage (during the main power pulse) of a single $D$-dot sensor is on the order of $100 \mathrm{~V}$; after the balun, the output voltage is $\sim 50 \mathrm{~V}$. (The balun reduces the signal by a factor of 2 since the null sensor of the $D$-dot monitor does not contribute to the signal.)

\section{RESULTS}

In this section we present power-flow data that were acquired on eight consecutive nominally identical $Z$-accelerator [1-9] shots. These are numbered 15421549. The load for these shots was a $z$-pinch-driven dynamic hohlraum [93-96]. The z-pinch configuration consisted of two nested 12-mm-length wire arrays. The masses of the outer and inner arrays were 2.4 and $1.2 \mathrm{mg}$, respectively; the initial array diameters were 40 and $20 \mathrm{~mm}$. The

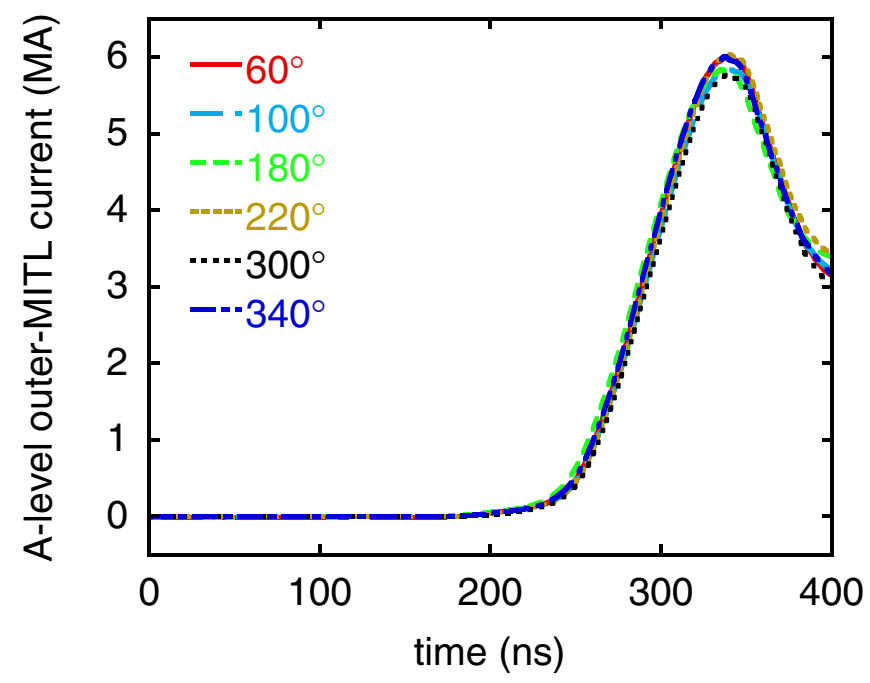

FIG. 14. (Color) Measurements on Z-shot 1548 of the A-level MITL current at 6 azimuthal locations.

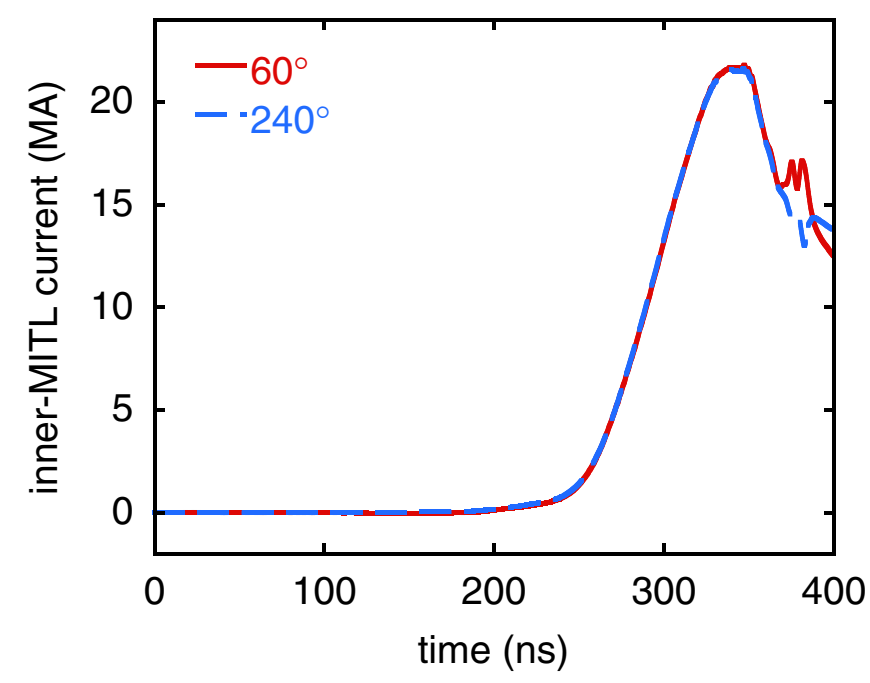

FIG. 15. (Color) Measurements on Z-shot 1548 of the innerMITL current at 2 azimuthal locations.

two arrays imploded upon a 6-mm-diameter $14-\mathrm{mg} / \mathrm{cm}^{3}$ $\mathrm{CH}_{2}$ foam cylinder located on axis [93-96]. (The load illustrated by Figs. 1 and 6 is a single wire array.)

Data acquired on $Z$-shot 1548 with the monitors described in Secs. I-V are presented by Figs. 12-16. Figures 12-14 present measurements of the D-level insulator-stack voltage, A-level insulator-stack current, and A-level outer-MITL current, respectively. (Level D has the highest voltage of the four levels; level A has the highest current.) Figure 15 plots the two inner-MITLcurrent measurements; Fig. 16 plots the total stack, outerMITL, and inner-MITL currents. For Figs. 12-16, the data were neither scaled nor time-shifted to facilitate the comparison of signals.

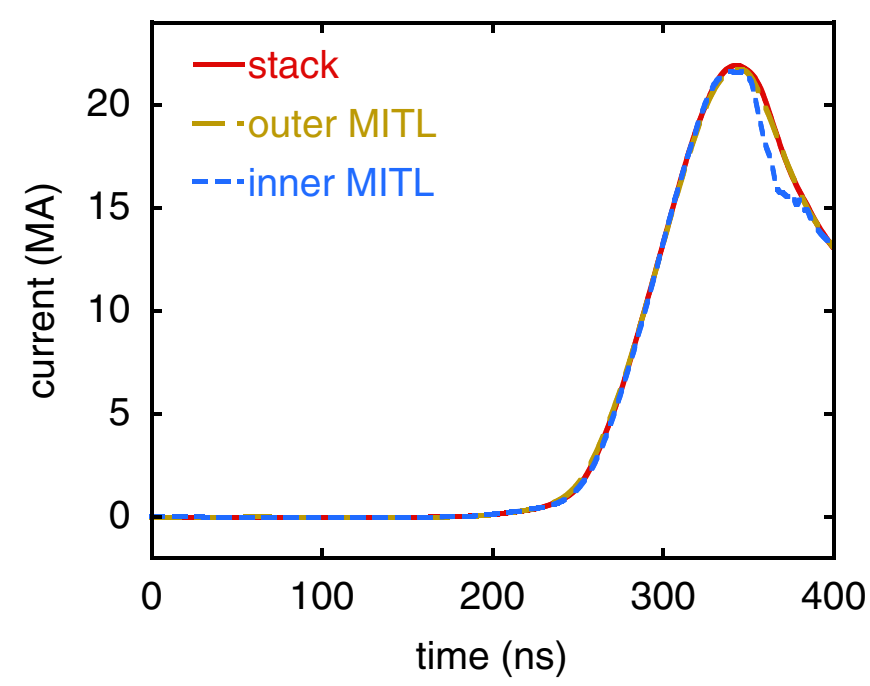

FIG. 16. (Color) Measurements on Z-shot 1548 of the total insulator-stack, outer-MITL, and inner-MITL currents. 
TABLE I. The mean and standard deviation of several measured quantities obtained on eight consecutive nominally identical Z-accelerator [1-9] shots. The load on these shots was a dynamic hohlraum driven by a wire-array $z$ pinch [93-96].

\begin{tabular}{lcc}
\hline \hline \multicolumn{1}{c}{ Quantity } & $\begin{array}{c}\text { Mean } \\
\text { value }\end{array}$ & $\begin{array}{c}\text { Standard } \\
\text { deviation } \\
(1 \sigma)\end{array}$ \\
\hline Peak insulator-stack current $I_{\text {stack }}$ & $21.84 \mathrm{MA}$ & $0.25 \mathrm{MA}(1.1 \%)$ \\
Peak outer-MITL current $I_{\text {outer }}$ & $21.65 \mathrm{MA}$ & $0.30 \mathrm{MA}(1.4 \%)$ \\
Peak inner-MITL current $I_{\text {inner }}$ & $21.71 \mathrm{MA}$ & $0.46 \mathrm{MA}(2.1 \%)$ \\
$I_{\text {outer }} / I_{\text {stack }}$ & 0.991 & $0.025(2.5 \%)$ \\
$I_{\text {inner }} / I_{\text {outer }}$ & 1.003 & $0.018(1.8 \%)$ \\
\hline \hline
\end{tabular}

The two current waveforms plotted by Fig. 15 show the Compton-drive component of the inner-MITL signals at time $t \sim 380 \mathrm{~ns}$. At this time the magnitude of the Compton drive is $13 \%$. Such Compton signals are caused by the pinch implosion on axis, which generates a $I_{\text {pinch }} d L_{\text {pinch }} / d t$ voltage spike, and an associated increase in the bremsstrahlung produced by the MITL flow electrons. As suggested by Figs. 15 and 16, combining the two inner-MITL $B$-dot signals as described in the last paragraph of Sec. IVA significantly reduces the Compton-drive component.

The total insulator-stack current plotted by Fig. 16 is the sum over the four accelerator levels of the azimuthally averaged current in each level. The total outer-MITL current is similarly constructed. The total inner-MITL current is numerically constructed from the two inner-MITL measurements, as discussed in the last paragraph of Sec. IVA. Table I lists results of peak-current measurements that were performed on shots 1542-1549. On these shots the peak lineal current densities at the insulator-stack, outer-MITL, and inner-MITL monitor locations were $0.5,1$, and $58 \mathrm{MA} / \mathrm{m}$, respectively. (We define the lineal current density to be the current divided by $2 \pi r$, where $r$ is the distance of the monitor from the central axis of the accelerator.)

The peak currents listed in Table I agree to within $1 \%$. Since the $z$-pinch load on these shots had a relatively low impedance, we expect from circuit simulations that the peak currents at the stack, outer-MITL, and inner-MITL locations would be the same to within a few percent, which is within the accuracy of the simulations. We caution, however, that agreement at the level indicated by Table I is fortuitous, since (as suggested by Appendix C) the $2 \sigma$ random uncertainty in the average value of 2 inner-MITL $B$-dot measurements performed on eight shots is estimated to be $\left(4.5 / 8^{1 / 2}\right) \%=1.6 \%$.

\section{DISCUSSION}

The diagnostic package outlined in Secs. I-V could be improved by increasing the number of monitors. This would increase the accuracy of the measurements on ac- celerator shots which (either intentionally or not) have a significant timing spread in the firing of the accelerator's modules, since such shots do not deliver an azimuthally symmetric power pulse to the accelerator's vacuum-powerflow section.

On such shots, azimuthal variations in current and voltage are significantly greater than indicated by Figs. $12-15$. Of course, large variations in the monitor signals compromise the accuracy of azimuthal averages calculated from the signals. Increasing the number of monitors would reduce the random uncertainty due to such variations, and the other sources of random error discussed in Appendix C. For example, since there are only two inner-MITL monitors, increasing their number to eight would significantly reduce their random error.

The dominant source of systematic error appears to be the $1.5 \%$ uncertainty in the self-calibration of the digital oscilloscopes, since this calibration error is also the dominant source of the systematic error of the attenuator values and monitor-calibration procedures (Appendix C). Hence, the accuracy of the measurements described herein could be improved if the scope-calibration error were to be reduced.

The inner-MITL current monitors attempt to measure the current $6 \mathrm{~cm}$ from the axis of the load, to which the $Z$ accelerator delivers as much as $2 \mathrm{MJ}$ in $100 \mathrm{~ns}$. Hence, these monitors are located in a harsh environment, one created by the high-electromagnetic-power densities in this region of the accelerator. The most serious difficulty facing these monitors appears to be damage caused by the flow electrons launched in the outer MITLs. As discussed in Sec. II and IVA, the upper convolute posts of Figs. 1 and 6 assist in shielding these monitors from the flow electrons. The inner-MITL-monitor performance could be improved if superior shielding techniques were to be developed.

We also mention that the signal cables of the outerMITL $B$-dots on levels $\mathrm{B}$ and $\mathrm{C}$ extend from the middle MITL anode to the middle insulator-stack anode, as suggested by Fig. 1. We caution that the cables and cable connections in this region must be carefully shielded, since the electrical connection between the middle-MITL and middle-stack anodes can be imperfect. In addition, it can be a challenge to maintain the integrity of the cables, connectors, and shielding in this region, since the MITLs are removed from the accelerator for refurbishment after every $Z$-accelerator shot.

Several other, less critical changes would improve the performance of the diagnostic package in a manner that might be significant for some applications. For example, the stack and outer-MITL $B$-dot monitors could be improved by laser welding the outer conductor of the semirigid coax to the copper body, instead of making this connection with silver epoxy. (Laser welding reduces contact resistance, and eliminates the chance that the silver epoxy could inadvertently flow across and short circuit one 
end, or both, of the coax.) We also note that the impedance of the short coaxial transmission line in the $D$-dot voltage monitor could be made equal to $50 \Omega$. This would eliminate high-frequency reflections due to the impedance mismatch between the monitor's present coaxial line and the 50- $\Omega$ SMA connector.

In addition, cancellation of common-mode noise in the $D$-dot monitor would be more effective if the stray capacitance of the end of the SMA barrel that is used as the null sensor were made equal to the stray capacitance of the $D$-dot sensor [97]. This would provide both coaxial cables connected to the monitor with more-similar terminating impedances. Noise generated in the cables and launched toward the monitor in the monitor's two cables would then be reflected from similar impedances, and be more effectively canceled by the balun.

\section{ACKNOWLEDGMENTS}

The authors gratefully acknowledge W. Ballard, J. Barth, W. Beezhold, T. Bock, J. Boyes, E. Breden, R. Brockman, P. Corcoran, D. Dalton, D. Droemer, S. Downie, J. Gergel, J. Gergel, Jr., C. Guthrie, R. Hanes-Michaud, E. Harlan, M. Harris, D. Jaramillo, D. Jobe, K. Jones, J. Kellogg, M. Kernaghan, F. Long, J. Lynch, M. Mazarakis, D. McDaniel, J. McKenney, G. Mowrer, T. Mullville, G. Olivas, M. Pelock, D. Petmecky, S. Ploor, J. Powell, J. Puissant, J. Ramirez, L. Reynolds, D. Rice, C. Robinson, M. Roderick, T. Romero, R. Ross, L. Schneider, J. H. Seamen, A. Seth, W. Simpson, I. Smith, J. Smith, R. Starbird, M. Sullivan, J. Webb, L. Wilson, A. York, and M. York, and our many other colleagues at Barth Electronics, C-Lec Plastics, EG\&G, Ktech Corporation, L-3 Communications, Mission Research Corporation, Prodyn Technologies, Sandia National Laboratories, Team Specialty Products, T\&M Research, Voss Scientific, and Votaw Precision Technologies, for invaluable contributions. We would also very much like to thank D. Sinars for graciously reviewing this article. Sandia is a multiprogram laboratory operated by Sandia Corporation, a Lockheed Martin Company, for the United States Department of Energy's National Nuclear Security Administration under Contract No. DE-AC04-94AL85000.

\section{APPENDIX A: NUMERICAL CABLE COMPENSATION}

This Appendix presents results of the numerical cablecompensation algorithm that we apply to a pulse transported by the coaxial-cable system used by an inner-MITL $B$-dot monitor. Similar cable-compensation results are obtained for the other monitors described in this article.

The components of an inner-MITL $B$-dot cable system are listed in Table II. Signals transported through this system are numerically cable compensated using the process described by Boyer [79]. The process makes use of a
TABLE II. Components of the coaxial-cable system used by an inner-MITL $B$-dot current monitor. The RG-405 cable connects to the monitor; the RG-223 cable connects to a transientwaveform-digitizing oscilloscope, which is located inside a double-wall screen room.

\begin{tabular}{lc}
\hline \hline \multicolumn{1}{c}{$\begin{array}{c}\text { Inner-MITL } B \text {-dot-monitor } \\
\text { coaxial-cable-system component }\end{array}$} & Length \\
\hline RG-405 (2.2-mm-diameter conformable cable) & $4.27 \mathrm{~m}$ \\
9914 (RG-8/U) & $10.67 \mathrm{~m}$ \\
12.7-mm-diameter Heliax & $28.96 \mathrm{~m}$ \\
RG-223 & $7.62 \mathrm{~m}$ \\
\hline \hline
\end{tabular}

step-function pulse. The pulse we use (which is plotted by Fig. 17) has a $10 \%-90 \%$ rise time of $1.3 \mathrm{~ns}$ and a peak amplitude of $0.5 \mathrm{~V}$. When the pulse is transported through the system delineated by Table II, the pulse suffers a significant reduction of its high-frequency components due to dissipative losses in the cables. The degradation is illustrated by Fig. 17. The undegraded and degraded pulses are used to generate a deconvolution function [79]; when the degraded pulse is deconvolved, the result obtained is the cable-compensated waveform plotted by the figure.

The $10 \%-90 \%$ rise time of the degraded waveform is $10.2 \mathrm{~ns}$; the rise time of the cable-compensated waveform is $1.7 \mathrm{~ns}$. Hence, the numerical-cable-compensation algo-

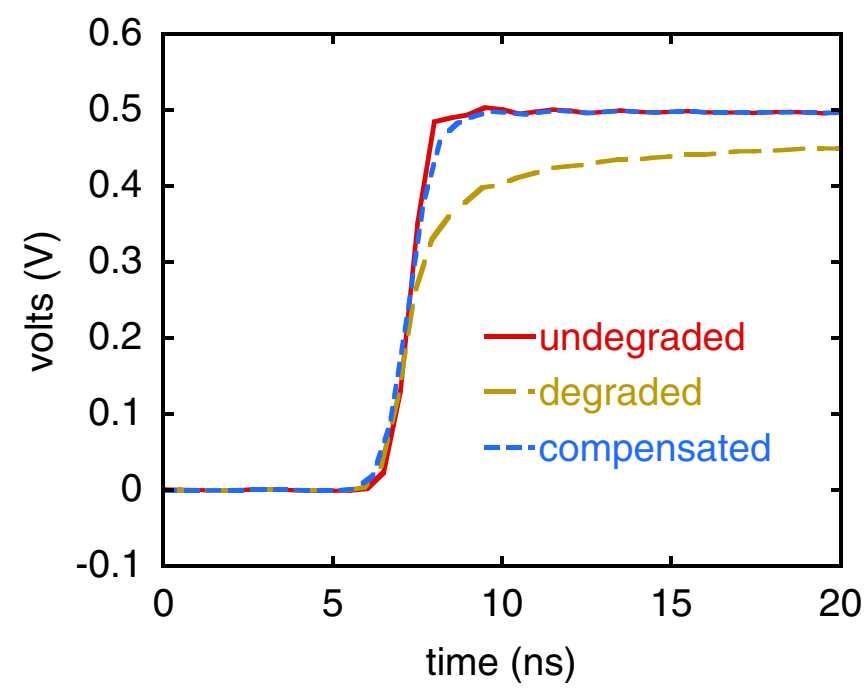

FIG. 17. (Color) Result of a numerical cable compensation [79] that is performed using a step-function voltage pulse. The undegraded pulse has a $10 \%-90 \%$ rise time of $1.3 \mathrm{~ns}$ and a peak voltage of $0.5 \mathrm{~V}$. When the pulse is transported through the coaxial-cable system delineated by Table II, the pulse suffers a significant reduction of its high-frequency components. Both the undegraded and degraded pulses are used to generate a deconvolution function for the coaxial-cable system [79]. The numerically compensated pulse plotted above is obtained by deconvolving the degraded pulse [79]. (The waveforms have been time shifted to facilitate comparisons.) 
TABLE III. Bandwidths and rise times of the components of an inner-MITL $B$-dot-monitor system. Assuming that the rise times add in quadrature, the total system bandwidth is approximately $173 \mathrm{MHz}$, and the $10 \%-90 \%$ system rise time is $2.0 \mathrm{~ns}$.

\begin{tabular}{lcc}
\hline \hline $\begin{array}{c}\text { Inner-MITL } B \text {-dot- } \\
\text { monitor-system component }\end{array}$ & $\begin{array}{c}\text { 3-dB } \\
\text { bandwidth }\end{array}$ & $\begin{array}{c}10 \%-90 \% \\
\text { rise time }\end{array}$ \\
\hline $\begin{array}{l}\text { Inner-MITL } B \text {-dot sensor } \\
\text { Coaxial-cable system }\end{array}$ & $\begin{array}{c}419 \mathrm{MHz} \\
\quad \text { after numerical }\end{array}$ & $\begin{array}{c}0.84 \mathrm{~ns} \\
\quad \text { cable compensation) }\end{array}$ \\
$\begin{array}{l}\text { Two attenuators in series } \\
\text { Digitizing oscilloscope }\end{array}$ & $\geq 2.8 \mathrm{MHz}$ \\
Total monitor system & $500 \mathrm{MHz}$ & $\leq 0.12 \mathrm{~ns}$ \\
\hline \hline
\end{tabular}

rithm developed by Boyer increases the effective bandwidth of the cable system by a factor of 6 .

\section{APPENDIX B: ESTIMATED MONITOR-SYSTEM RISE TIME}

The principal components of an inner-MITL $B$-dotmonitor system, their bandwidths, and their rise times are listed in Table III. The components of the other monitor systems described in this article have comparable bandwidths and rise times.

Using inductance relations given by Knoepfel [27], we estimate that the inductance of the inner-MITL $B$-dot sensor $L$ is $19 \mathrm{nH}$; hence, Eq. (6) suggests that the $10 \%-$ $90 \%$ rise time of the sensor is $0.84 \mathrm{~ns}$. Assuming that the rise times of the components listed in Table III add in quadrature, the rise time of the inner-MITL $B$-dot system is approximately $2.0 \mathrm{~ns}$.

\section{APPENDIX C: ESTIMATED SYSTEMATIC AND RANDOM ERRORS}

Estimated systematic and random uncertainties of the inner-MITL $B$-dot monitor are listed in Table IV. The other monitors described in this article have similar uncertainties.

The $2 \sigma$ random uncertainty in the average value of 2 inner-MITL $B$-dot-monitor signals is estimated to be $4.5 \%$. If the number of inner-MITL monitors were to be increased to 8 , the random uncertainty would decrease to $2.2 \%$.

\section{APPENDIX D: COMPTON CABLE DRIVE AND THE EFFECTIVENESS OF COMMON-MODE- NOISE REJECTION}

The MITLs of the $Z$ accelerator launch electron-flow current, a large fraction of which eventually strikes the anodes of the MITL system and generates bremsstrahlung. The radiation in turn interacts via the Compton effect with electrons in the coaxial cables connected to the $B$-dot and $D$-dot monitors described in this article.
TABLE IV. Estimated systematic and random errors of the inner-MITL $B$-dot current monitor. The systematic calibration error includes that due to differences between the calibrationsystem and inner-MITL geometry. The random error due to azimuthal variations is inferred from the measurements presented in Sec. VI. The estimated total random error $(2 \sigma)$ in the average value of two inner-MITL $B$-dots is estimated to be $4.5 \%$. The total random error would decrease to $2.2 \%$ for eight $B$-dots.

\begin{tabular}{lcc}
\hline \hline $\begin{array}{l}\text { Inner-MITL } B \text {-dot-monitor } \\
\text { error source }\end{array}$ & $\begin{array}{c}\text { Estimated } \\
\text { systematic } \\
\text { error }(2 \sigma)\end{array}$ & $\begin{array}{c}\text { Estimated } \\
\text { random } \\
\text { error }(2 \sigma)\end{array}$ \\
\hline $\begin{array}{l}\text { Calibration } \\
\text { Numerical cable compensation }\end{array}$ & $3 \%$ & $2 \%$ \\
Attenuators & $1 \%$ & $1 \%$ \\
Digitizing oscilloscope & $2 \%$ & $2 \%$ \\
Common-mode signals & $1.5 \%$ & $1.5 \%$ \\
$\quad$ (such as those due to & $2 \%$ & $2 \%$ \\
$\quad \begin{array}{l}\text { Compton drive, ground loops, } \\
\text { imperfect shielding, etc.) } \\
\text { after the inner-MITL } B \text {-dot } \\
\text { signals have been processed } \\
\text { as discussed in Sec. IVA }\end{array}$ & & \\
Random azimuthal variation & & \\
in the current & & \\
Total estimated error $(2 \sigma)$ for \\
the average of two inner-MITL \\
$B$-dots
\end{tabular}

The Compton electrons induce a negative-polarity voltage pulse in both cables that are attached to each differential-output monitor. The voltage is added to the signals produced by the monitor's two sensors. The two cables are connected to a balun. The balun attenuates each signal by a factor of 2 , inverts one of the two signals, adds it to the other, and delivers the sum to the output connector of the balun. Hence to first order, the balun removes the Compton-electron-induced signals (and other commonmode signals) from the output signal. [The inner-MITL $B$-dot monitor described in this article is not, by itself, a differential-output detector; hence, two such monitors are fielded with opposite polarities. Common-mode signals are removed (to first order) by performing the operation described above numerically, without use of a balun, as described in the last paragraph of Sec. IVA.]

We discuss below the effectiveness of this process for the insulator-stack $D$-dots fielded on the D-level of the $Z$ accelerator. Comparable results are obtained for the other monitors described in this article.

Most of the Compton signal generated in the cables attached to a $D$-dot monitor is produced in a 2-m-length section of 2.2-mm-diameter RG-405 coaxial cable. This cable section is located in a hard-x-ray-radiation environ- 
ment in which the absorbed dose to calcium-fluoride thermoluminescent detectors is on the order of $1 \mathrm{~Gy}$ (100 rads). On a typical $Z$-accelerator shot, the total time-integrated Compton current generated in such a cable is $3.2 \mathrm{nC}$; i.e., $1.6 \mathrm{nC}$ is launched in each of the cable's two directions. The Compton signal peaks at $\sim 4$ volts.

Without common-mode rejection, the Compton contribution to the total signal generated by a monitor (after the signal is integrated) is $10 \%$; the balun reduces the Compton contribution to $0.3 \%$. When 3.6-mm-diameter cable (RG402) is used instead of RG-405, the Compton signal increases a factor of 1.7; however, the larger-diameter cable has a superior frequency response.

The optimum cable choice for a given experiment is, of course, determined by the experiment's specific requirements. For experiments conducted on the $Z$ accelerator, 2.2-mm-diameter RG-405 cable provides reasonable overall performance throughout $Z$ 's vacuum section. However, it is clear that other applications with different bremsstrahlung environments, and accuracy and bandwidth requirements, may find that a different cable choice offers superior system performance.

[1] R. B. Spielman, W. A. Stygar, J. F. Seamen, F. Long, H. Ives, R. Garcia, T. Wagoner, K. W. Struve, M. Mostrom, I. Smith, P. Spence, and P. Corcoran, in Proceedings of the 11th IEEE International Pulsed Power Conference, edited by G. Cooperstein and I. Vitkovitsky (IEEE, Piscataway, NJ, 1997), p. 709.

[2] P. A. Corcoran, J. W. Douglas, I. D. Smith, P. W. Spence, W. A. Stygar, K. W. Struve, T. H. Martin, R. B. Spielman, and H.C. Ives, in Proceedings of the 11th IEEE International Pulsed Power Conference (Ref. [1]), p. 466.

[3] R. J. Garcia, H. C. Ives, K. W. Struve, R. B. Spielman, T.H. Martin, M.L. Horry, R. Wavrik, and T.F. Jaramillo, in Proceedings of the 11th IEEE International Pulsed Power Conference (Ref. [1]), p. 1614.

[4] H. C. Ives, D. M. Van De Valde, F. W. Long, J. W. Smith, R. B. Spielman, W. A. Stygar, R. W. Wavrick, and R. W. Shoup, in Proceedings of the 11th IEEE International Pulsed Power Conference (Ref. [1]), p. 1602.

[5] M. A. Mostrom, T. P. Hughes, R. E. Clark, W. A. Stygar, and R. B. Spielman, in Proceedings of the 11th IEEE International Pulsed Power Conference (Ref. [1]), p. 460.

[6] R. W. Shoup, F. Long, T. H. Martin, R. B. Spielman, W. A. Stygar, M.A. Mostrom, K. W. Struve, H. Ives, P. Corcoran, and I. Smith, in Proceedings of the 11 th IEEE International Pulsed Power Conference (Ref. [1]), p. 1608 .

[7] I. D. Smith, P. A. Corcoran, W. A. Stygar, T. H. Martin, R. B. Spielman, and R. W. Shoup, in Proceedings of the 11th IEEE International Pulsed Power Conference (Ref. [1]), p. 168.

[8] K. W. Struve, T. H. Martin, R. B. Spielman, W. A. Stygar, P. A. Corcoran, and J. W. Douglas, in Proceedings of the 11th IEEE International Pulsed Power Conference (Ref. [1]), p. 162.
[9] W. A. Stygar, R. B. Spielman, G. O. Allshouse, C. Deeney, D. R. Humphreys, H. C. Ives, F. W. Long, T. H. Martin, M. K. Matzen, D. H. McDaniel, C. W. Mendel, Jr., L. P. Mix, T. J. Nash, J. W. Poukey, J. J. Ramirez, T. W. L. Sanford, J. F. Seamen, D. B. Seidel, J. W. Smith, D. M. Van De Valde, R. W. Wavrik, P. A. Corcoran, J.W. Douglas, I. D. Smith, M. A. Mostrom, K. W. Struve, T. P. Hughes, R. E. Clark, R. W. Shoup, T. C. Wagoner, T. L. Gilliland, and B. Peyton, in Proceedings of the 11th IEEE International Pulsed Power Conference, Baltimore (Ref. [1]), p. 591.

[10] W. A. Stygar, R. B. Spielman, H. C. Ives, W. B. S. Moore, J. F. Seamen, A. W. Sharpe, T. C. Wagoner, T. L. Gilliland, R. S. Broyles, J. A. Mills, T. A. Dinwoodie, J. S. Slopek, K. W. Struve, and P. G. Reynolds, in Proceedings of the 11th IEEE International Pulsed Power Conference (Ref. [1]), p. 1258.

[11] W. A. Stygar, H. C. Ives, D. L. Fehl, M. E. Cuneo, M. G. Mazarakis, J. E. Bailey, G. R. Bennett, D. E. Bliss, G. A. Chandler, R. J. Leeper, M. K. Matzen, D. H. McDaniel, J. S. McGurn, J. L. McKenney, L. P. Mix, D. J. Muron, J. L. Porter, J. J. Ramirez, L. E. Ruggles, J. F. Seamen, W. W. Simpson, C. S. Speas, R. B. Spielman, K. W. Struve, J. A. Torres, R. A. Vesey, T. C. Wagoner, T. L. Gilliland, M. L. Horry, D. O. Jobe, S. E. Lazier, J. A. Mills, T. D. Mulville, J. H. Pyle, T. M. Romero, J. J. Seamen, and R. M. Smelser, Phys. Rev. E 69, 046403 (2004).

[12] W. A. Stygar, M. E. Cuneo, R. A. Vesey, H. C. Ives, M. G. Mazarakis, G. A. Chandler, D. L. Fehl, R. J. Leeper, M. K. Matzen, D. H. McDaniel, J. S. McGurn, J. L. McKenney, D. J. Muron, C. L. Olson, J. L. Porter, J. J. Ramirez, J. F. Seamen, C. S. Speas, R. B. Spielman, K. W. Struve, J. A. Torres, E. M. Waisman, T. C. Wagoner, and T. L. Gilliland, Phys. Rev. E 72, 026404 (2005).

[13] E. M. Waisman, M. E. Cuneo, W. A. Stygar, R. W. Lemke, and K. W. Struve, Phys. Plasmas 11, 2009 (2004).

[14] R. B. Spielman, P. Corcoran, J. Fockler, H. Kishi, and P.W. Spence, in Proceedings of the 7th IEEE International Pulsed Power Conference, edited by B. H. Bernstein and J. P. Shannon (IEEE, Piscataway, NJ, 1989), p. 445.

[15] T.P. Hughes and R.E. Clark, Mission Research Corporation Report MRC/ABQ-R-1875, 1998.

[16] T.P. Hughes and R.E. Clark, Mission Research Corporation Report No. MRC/ABQ-R-2005, 2000.

[17] T. P. Hughes, R. E. Clark, B. V. Oliver, R. A. St. John, and W. A. Stygar, Mission Research Corporation Report No. MRC/ABQ-R-2066, 2002.

[18] T. D. Pointon, W. A. Stygar, R. B. Spielman, H. C. Ives, and K. W. Struve, Phys. Plasmas 8, 4534 (2001).

[19] D. V. Rose, D. R. Welch, T. P. Hughes, R. E. Clark, C. B. Mostrom, and W. A. Stygar, in Proceedings of the 16th IEEE International Pulsed Power Conference, edited by E. Schamiloglu and F. Peterkin (IEEE, Piscataway, NJ, 2007), p. 171.

[20] D. V. Rose, D. R. Welch, T. P. Hughes, R. E. Clark, and W. A. Stygar, Phys. Rev. ST Accel. Beams 11, 060401 (2008).

[21] G.E. Rochau, G. R. Mowrer, and J.A. Webb, IEEE Conference Record of the Workshop on Measurements of Electrical Quantities in Pulse Power Systems II, edited by 
R. H. McKnight (IEEE, New York, 1988), p. 45.

[22] W. Rogowski and W. Steinhaus, Arch. Elektrotech. 1, 141 (1912).

[23] R. C. Fletcher, Rev. Sci. Instrum. 20, 861 (1949).

[24] J. Cooper, J. Nucl. Energy, Part C 5, 285 (1963).

[25] Plasma Diagnostic Techniques, edited by R.H. Huddlestone and S.L. Leonard (Academic, New York, 1965).

[26] G.E. Leavitt, J.D. Shipman, Jr., and I. M. Vitkovistky, Rev. Sci. Instrum. 36, 1371 (1965).

[27] H. Knoepfel, Pulsed High Magnetic Fields (NorthHolland, London, 1970).

[28] D. Pellinen, Rev. Sci. Instrum. 41, 1347 (1970).

[29] J. M. Anderson, Rev. Sci. Instrum. 42, 915 (1971).

[30] D. G. Pellinen, Rev. Sci. Instrum. 42, 667 (1971).

[31] D. G. Pellinen and S. Heurlin, Rev. Sci. Instrum. 42, 824 (1971).

[32] D. G. Pellinen and P.W. Spence, Rev. Sci. Instrum. 42, 1699 (1971).

[33] W. C. Condit, Jr. and D. Pellinen, Phys. Rev. Lett. 29, 263 (1972).

[34] T. J. Fessenden, Rev. Sci. Instrum. 43, 1090 (1972).

[35] T. J. Fessenden, B. W. Stallard, and G. G. Berg, Rev. Sci. Instrum. 43, 1789 (1972).

[36] D. G. Pellinen and I. Smith, Rev. Sci. Instrum. 43, 299 (1972).

[37] D. G. Pellinen, Rev. Sci. Instrum. 43, 1181 (1972).

[38] D. Pellinen, Rev. Sci. Instrum. 43, 1654 (1972).

[39] W. C. Condit, Jr., D. O. Trimble, G. A. Metzger, D. G. Pellinen, S. Heurlin, and P. Creely, Phys. Rev. Lett. 30, 123 (1973).

[40] D. Pellinen and V. Staggs, Rev. Sci. Instrum. 44, 46 (1973).

[41] D. G. Pellinen and S.E. Heurlin, IEEE Trans. Nucl. Sci. 20, 333 (1973).

[42] N. W. Harris, Rev. Sci. Instrum. 45, 961 (1974).

[43] D. Honea and S.S. Medley, J. Phys. E 7, 537 (1974).

[44] D. G. Pellinen, Q. Johnson, and A. Mitchell, Rev. Sci. Instrum. 45, 944 (1974).

[45] C. W. Mendel, Jr., Rev. Sci. Instrum. 46, 847 (1975).

[46] S. Shope, J. W. Poukey, K. D. Bergeron, D. H. McDaniel, A. J. Toepfer, and J.P. VanDevender, J. Appl. Phys. 49, 3675 (1978).

[47] R. L. Copeland, J. L. Adamski, W. O. Doggett, D. L. Morrow, and W.H. Bennett, Rev. Sci. Instrum. 50, 233 (1979).

[48] M. S. Di Capua and D. G. Pellinen, J. Appl. Phys. 50, 3713 (1979).

[49] V. Nassisi and A. Luches, Rev. Sci. Instrum. 50, 900 (1979).

[50] C. Ekdahl, Rev. Sci. Instrum. 51, 1645 (1980).

[51] C. Ekdahl, Rev. Sci. Instrum. 51, 1649 (1980).

[52] D. G. Pellinen and M. S. Di Capua, Rev. Sci. Instrum. 51, 70 (1980).

[53] D. G. Pellinen, M. S. Di Capua, S.E. Sampayan, H. Gerbracht, and M. Wang, Rev. Sci. Instrum. 51, 1535 (1980).

[54] G. Gerdin, W. Stygar, and F. Venneri, J. Appl. Phys. 52, 3269 (1981).
[55] J.L. Pack and I. Liberman, Rev. Sci. Instrum. 52, 1580 (1981).

[56] Proceedings of the Workshop on Measurements of Electrical Quantities in Pulse Power Systems (NBS-SP628), edited by R.H. McKnight and R.E. Hebner, Jr. (National Bureau of Standards, Washington, DC, USA, 1982).

[57] R. W. Stinnett and T. Stanley, J. Appl. Phys. 53, 3819 (1982).

[58] W. Stygar and G. Gerdin, IEEE Trans. Plasma Sci. 10, 40 (1982).

[59] A. I. Gerasimov and E. G. Dubinov, Instrum. Exp. Tech. 26, 392 (1983).

[60] C. Ekdahl, Rev. Sci. Instrum. 55, 1221 (1984).

[61] J. Maenchen, H. T. Sheldon, G. D. Rondeau, J. B. Greenly, and D. A. Hammer, Rev. Sci. Instrum. 55, 1931 (1984).

[62] N. G. Pavlovskaya and S. L. Él'yash, Instrum. Exp. Tech. 27, 1174 (1984).

[63] R. J. Leeper, J.R. Lee, L. Kissel, D. J. Johnson, W. A. Stygar, and D.E. Hebron, J. Appl. Phys. 60, 4059 (1986).

[64] G. A. Rochau and G. R. Mowrer, IEEE Conference Record of the Workshop on Measurements of Electrical Quantities in Pulse Power Systems II, edited by R. H. McKnight (IEEE, Piscataway, NJ, 1986), p. 25.

[65] D. L. Hanson, R. R. Williams, J. L. Porter, R. B. Spielman, and M. K. Matzen, J. Appl. Phys. 68, 4917 (1990).

[66] M.E. Savage, C. W. Mendel, Jr., T.W. Grasser, W.W. Simpson, and D. M. Zagar, Rev. Sci. Instrum. 61, 3812 (1990).

[67] T.W.L. Sanford et al., Rev. Sci. Instrum. 63, 4795 (1992).

[68] A. I. Gerasimov, Instrum. Exp. Tech. 36, 236 (1993).

[69] A. I. Gerasimov, Instrum. Exp. Tech. 37, 80 (1994).

[70] J. Chang, G. Allen, W. F. Filter, G. J. Lockwood, and B. T. Neyer, in Proceedings of the 5th IEEE International Pulsed Power Conference, edited by M. F. Rose and P. J. Turchi (IEEE, Piscataway, NJ, 1995), p. 1.

[71] P. Choi and M. Favre, in Proceedings of the 10th IEEE International Pulsed Power Conference, edited by W. Baker and G. Cooperstein (IEEE, Piscataway, NJ, 1995), p. 880 .

[72] B. T. Neyer, J. Chang, G. J. Lockwood, and L. E. Ruggles, in Proceedings of the 5th IEEE International Pulsed Power Conference, edited by M. F. Rose and P. J. Turchi (IEEE, Piscataway, NJ, 1995), p. 389.

[73] I. H. Mitchell, J. M. Bayley, J.P. Chittenden, J. F. Worley, A.E. Dangor, M. G. Haines, and P. Choi, Rev. Sci. Instrum. 67, 1533 (1996).

[74] Jian-Zhong Bao, Rev. Sci. Instrum. 68, 2221 (1997).

[75] K.W. Struve, M.L. Horry, and R. B. Spielman, in Proceedings of the 11th IEEE International Pulsed Power Conference (Ref. [1]), p. 1303.

[76] A. I. Gerasimov, Instrum. Exp. Tech. 41, 228 (1998).

[77] C. Ekdahl, Rev. Sci. Instrum. 72, 2909 (2001).

[78] C. Ekdahl, Rev. Sci. Instrum. 76, 095108 (2005).

[79] W. B. Boyer, Sandia National Laboratories Report No. SAND87-3072, 1987.

[80] MWS Wire Industries, Westlake Village, California, USA, www.mwswire.com. 
[81] Tra-Con, Inc., Bedford, Massachusetts, USA, www. tra-con.com.

[82] Prodyn Technologies, Inc., Albuquerque, New Mexico, USA, www.prodyntech.com.

[83] C. L. Ruiz and D. F. Wenger, Sandia National Laboratories Report No. SAND85-0616, 1985, p. 85.

[84] W. P. Ballard and J. J. Hohlfelder (private communication).

[85] Barth Electronics, Inc., Boulder City, Nevada, USA, www.barthelectronics.com.

[86] Aeroflex/Weinschel, Inc., Frederick, Maryland, USA, www.aeroflex-weinschel.com.

[87] Tektronix, Inc., Beaverton, Oregon, USA, www.tek.com.

[88] Teledyne Reynolds, Inc., Los Angeles, California, USA, www.teledynereynolds.com.

[89] T\&M Research Products, Inc., Albuquerque, New Mexico, USA, www.tandmresearch.com.

[90] L. P. Mix (unpublished).

[91] Integrated Engineering Software, Winnipeg, Manitoba, Canada, www.integratedsoft.com.

[92] AMP products are fabricated by Tyco Electronics (www.tycoelectronics.com) and can be purchased from Hawk Electronics, Wheeling, Illinois, USA, www. hawkusa.com.

[93] T. W. L. Sanford, R. W. Lemke, R.C. Mock, G. A. Chandler, R. J. Leeper, C.L. Ruiz, D. L. Peterson, R. E. Chrien, G. C. Idzorek, R. G. Watt, and J.P. Chittenden, Phys. Plasmas 9, 3573 (2002).

[94] J.E. Bailey et al., Phys. Plasmas 13, 056301 (2006).

[95] S. A. Slutz, K. J. Peterson, R. A. Vesey, R. W. Lemke, J. E. Bailey, W. Varnum, C. L. Ruiz, G.W. Cooper, G. A. Chandler, G. A. Rochau, and T. A. Mehlhorn, Phys. Plasmas 13, 102701 (2006).

[96] G. A. Rochau, J.E. Bailey, G. A. Chandler, G. Cooper, G. S. Dunham, P. W. Lake, R. J. Leeper, R. W. Lemke, T. A. Mehlhorn, A. Nikroo, K. J. Peterson, C. L. Ruiz, D. G. Schroen, S. A. Slutz, D. Steinman, W. A. Stygar, and W. Varnum, Plasma Phys. Controlled Fusion 49, B591 (2007).

[97] I. D. Smith (private communication). 